This document is the accepted manuscript version of the following article:

Kenway, S. J., Scheidegger, R., Larsen, T. A., Lant, P., \& Bader, H. P. (2013). Water-

related energy in households: a model designed to understand the current state and simulate possible measures. Energy and Buildings, 58, 378-389.

https://doi.org/10.1016/j.enbui 1d.2012.08.035

This manuscript version is made available under the CC-BY-NC-ND 4.0

license http://creativecommons.org/1icenses/by-nc-nd/4.0/

\title{
Water-related energy in households: a model designed to understand the current state and simulate possible measures
}

\author{
Kenway, Steven. J.; Scheidegger, Ruth; Larsen, Tove A.; Lant, Paul; Bader, Hans-Peter.
}

\begin{abstract}
Energy use and the associated greenhouse gas emissions are very high in industrialised countries. Energy use in households, including private transport, accounts for about $30 \%$ of primary energy. Therefore households are important key drivers of energy use and related greenhouse gas emissions. To influence household consumption, it is important to gain an insight into the different uses within the household. One of these uses is water and water-related energy, which is the topic of this paper.

To address this topic, a detailed mathematical flow analysis of materials, energy, $\mathrm{CO}_{2}$ emissions and costs (MMFA) for household water use was set up and tested for a specific family household in Brisbane, Australia. The simulation results for the current state of this household were well within $20 \%$ of the monitored data. After calibration, a detailed scenario investigation was performed to determine the impact of (i) potential and (ii) realistic reduction values for all relevant (a) behavioural and (b) technical parameters, including a shift from gas to a solar hot-water system. The reduction potentials for water use, greenhouse gas emissions, water-related energy consumption, water costs and water-related energy costs were $4-77 \%, 14-85 \%, 15-93 \%, 1-31 \%$ and $13-$ $90 \%$ respectively, depending on the measures taken. The study showed that for this specific household, technical improvements alone, without changing to a solar hot-water system, result in less than a $15 \%$ change in terms of energy and greenhouse gas emissions. In contrast, combined behavioural and technical changes have a much higher reduction potential. The model is designed so that it can also be used to simulate other household types as well as whole cities.
\end{abstract}

Keywords: Water, energy, greenhouse gas emissions, material flow analysis, modelling.

\section{Introduction}

The consumption of energy and the associated greenhouse gas emissions are very high in industrialised countries. In Australia, primary energy consumption in 2007-08 was about $8 \mathrm{~kW}$ per person (around 68,000 $\mathrm{kWh}$ per person and year or 1,463,900 GWh/year of total domestic use [1, 2]). This is around four times higher than the global average of $2 \mathrm{~kW}$ per person [3]. This figure has been suggested as the future goal for countries currently consuming high amounts of energy. The unit of $\mathrm{W}$ per person is a convenient way to measure and compare energy consumption. A figure of $1 \mathrm{~kW}$ per person corresponds to $8,760 \mathrm{kWh}$ per person and year. This consumption unit was introduced in the "trilennium symposium" held in Japan in 1996 [4] to characterise a society according to its energy consumption.

The corresponding figure for greenhouse gas emissions (from energy consumption) for Australia is about 26,500 $\mathrm{kg} \mathrm{CO}_{2}$ equivalent per person and year $\left(576 \times 10^{6} \mathrm{t}\right.$ per year for the whole country [5]).

Like other countries, Australia has set targets for reducing these emissions. In order to reduce energy consumption, an overview and insight into its different contributions is necessary. Private households in Australia consumed about $19,700 \mathrm{kWh} /$ person and year of primary energy corresponding to about 2.2 $\mathrm{kW} /$ person. This includes private transport, which accounts for about $11,000 \mathrm{kWh} /$ person and year $(1.3$ $\mathrm{kW} /$ person) [1]. Industry consumed about $32,600 \mathrm{kWh} /$ person and year of primary energy $(3.7 \mathrm{~kW} /$ person), including industry-related transport. Commercial and public services, agriculture and forestry, fishing and nonenergy use account for the rest $(1.8 \mathrm{~kW} /$ person).

According to [6], water-related energy consumption in Australian cities accounts for about $6,800 \mathrm{kWh}$ (or 10\%) of total primary energy per person $(0.78 \mathrm{~kW} /$ person). Households account for about $30 \%$ of water-related energy consumption. This amounts to $2,040 \mathrm{kWh}$ per person and year $(0.23 \mathrm{~kW} /$ person $)$ of primary energy $(10 \%$ of primary household energy).

Private households are important key drivers since they can determine their consumption in two ways: i) directly by regulating their direct energy consumption (mobility, heating/cooling, housing etc.), and ii) indirectly by regulating their grey energy consumption (amount, origin, quality and lifetime of everyday products).

This study consequently focuses on private households, and in particular on their water-related energy consumption and greenhouse gas emissions. Unlike sectors such as mobility, heating/cooling and communications, water-related energy consumption in households has not been studied very intensively. Household water use is very important in itself quite apart from the aspect of energy consumption. From 20012008, the historic "millennium" drought [7] made the citizens of Australia even more aware of their limited water availability. Water consumption was drastically cut from about 300 to about 2201 per capita and day. More sustainable water consumption would have many advantages: a) reduction of water-related energy use and 
greenhouse gas emissions, b) lower costs for freshwater and wastewater, c) less infrastructure and lower costs for water infrastructure.

In the past ten years, few studies have been undertaken that focus on water-related energy in households. Cheng [8] investigated the relationship between water use and energy consumption in buildings. He found that $84 \%$ of water-related energy (including energy for treatment and transport of water and wastewater) is used for water heating, and the largest share comes from taking showers. He also suggested that energy loss (water cooling in pipes, boilers) could be significant. Arpke [9] used data mining to model four household types in the US Midwest to show that energy uses for heating water comprised $97 \%$ of water-related energy.

Flower [10] developed a model based on data mining to simulate three "average" household types in Victoria, Australia, having an instantaneous hot water system running on either i) electricity, ii) gas storage or iii) natural gas. The model was based on the work of Arpke [9], other previous studies [11-17] and data mining. He found that $86-90 \%$ of the energy consumed in the urban water cycle is used for water heating in households. The operation of mechanical appliances accounted for $6-8 \%$. Less than $4 \%$ of the energy was associated with the treatment and transport of water and wastewater. The hot water energy use was dominated by showers followed by washing machines and indoor taps. Greenhouse gas emissions were also dominated by showers, followed by washing machines. Showers and washing machines constituted a particularly large fraction of total water-related greenhouse gas emissions in households with an electric hot water system. In households with a natural-gas hot water system, the greenhouse gas burden of showers and washing machines was followed much more closely by emissions from dishwashers and evaporative air-conditioners. Flower extended his findings for the three household types to a city-scale assessment using probability distributions to include variations between single households.

The aim of this study is to develop and apply a model for water use, water-related energy as well as related $\mathrm{CO}_{2}$ emissions and costs that is applicable to any single household as well as on a city scale. The model should take into account all relevant contributions to residential water use. It should provide a system understanding of water-related household activities and should answer the following questions:

(1) What are the most relevant contributions to water use, water-related energy use and greenhouse gas emissions in households?

(2) What are the key drivers of these flows?

(3) What possible measures could be applied to reduce these flows?

Moreover, the model should improve the basis for household monitoring and contribute to the development and design of more sustainable homes of the future.

The model is a systematic description of all residential water and water-related energy use. Each use was broken down in terms of its key driving factors. This provides a profound system understanding and allows any change in technology and behaviour to be analysed at household level.

\section{Research Method and Model}

In this study, we used a mathematical material flow analysis (MMFA) to quantify the household flows of water and energy. The approach is an extension of the classical MFA developed in the economic sector in the 1950s [18] and later adapted to regional investigations [19]. More recently, it has been applied to solving diverse environmental problems [20-22]. As pointed out by Schaffner et al. [22], the key benefit of the method is its ability to provide an understanding of the system based on current knowledge using often scarcely available data rather than conducting large monitoring and data collection campaigns. The method further aims to identify the key parameters (driving forces) involved. This is crucial for discussing possible measures (scenarios) to reduce the flows. The MMFA comprised the following steps:

1) System analysis

2) Mathematical model

3) Data collection and calibration

4) Simulation including uncertainty analysis, sensitivity analysis and scenario calculations.

\subsection{System analysis}

The system border and the balance volumes and flows appropriate to the system have to be defined. The aim was to describe not only one specific household but the most common types found in Australian cities. Therefore the system had to be designed to include different supply systems (electricity, gas, etc.) for the equipment as well as different equipment (e.g. top or front-loading washing machines). On the basis of our analysis, we set up the system shown in Fig. 1. The core of the system comprises ten "service" subsystems 
shaded in grey. The subsystems provide the households with water-related services such as drinking water, water for laundering and dishwashing, water to flush toilets etc. The exception is the "other energy" subsystem which captures all other major household energy-using services. The "service" subsystems are supplied with water and energy from the supply subsystems.

Wastewater from the "service" subsystems is discharged to the wastewater subsystem. The associated major flows of cold and hot water, energy and wastewater were identified. In order to validate the findings against household water and energy use records, all significant water and energy uses in the household must be included in the analysis.

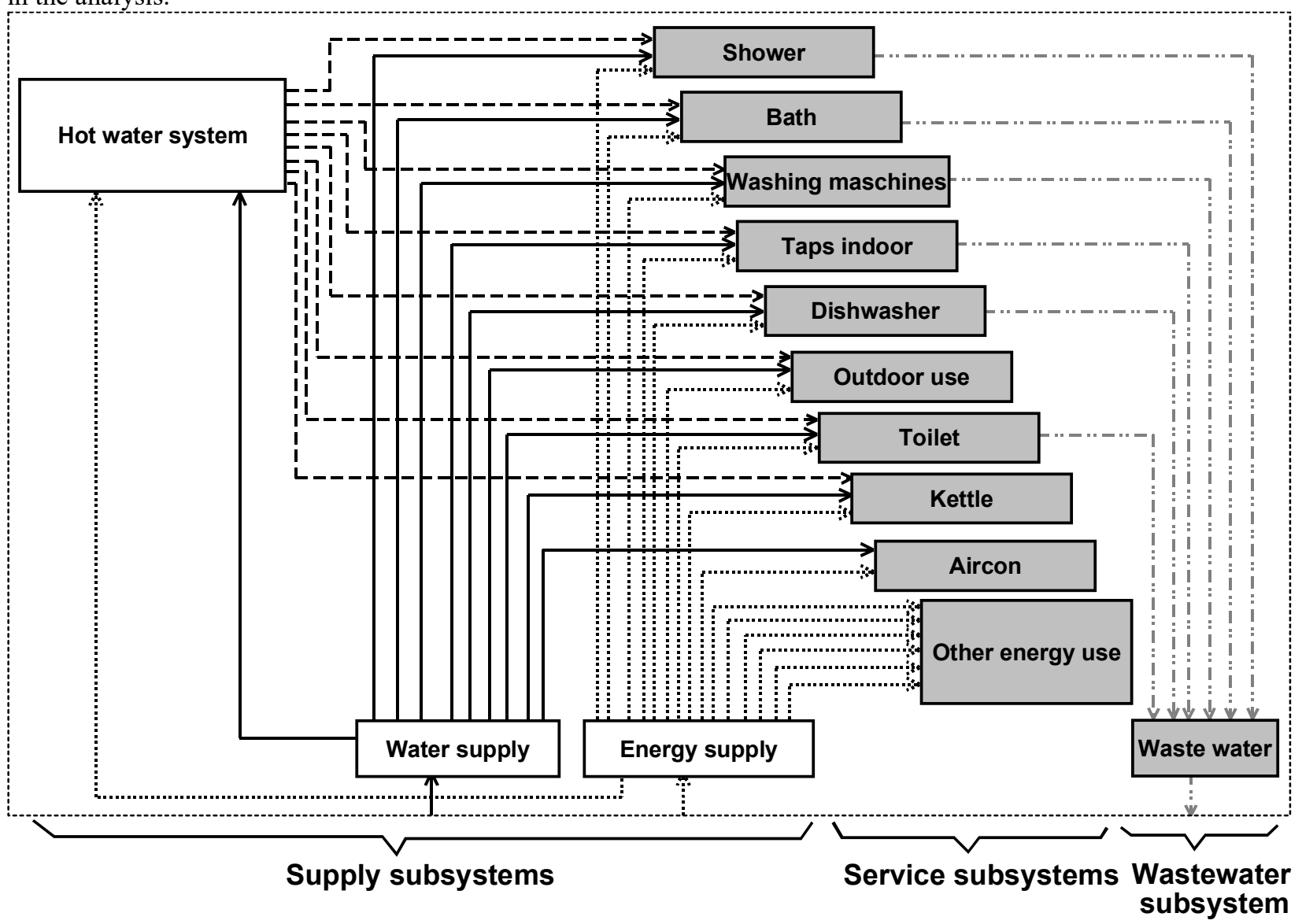

Figure 1: Scheme of the system showing tracked service, supply and wastewater subsystems and flows including cold water, hot water (dashed), energy (dotted), and wastewater (greyed).

Importantly, by tracking each individual flow, the approach creates a wide ability to assess and consider the influence of detailed alterations at subsystem level, such as including altered technologies, behaviours or environmental conditions.

\subsection{Mathematical model}

The model equations describe the present knowledge of the system.

We have chosen a "demand-driven" approach. This means that the specific demands on cold and hot water of the different subsystems providing the service required by the households are at the core of the model. For example, each individual resident requires a certain "shower service" characterised by duration, temperature of water, flow rate and frequency per day (shower parameters). This detailed approach is challenging as it requires information on a large range of parameters. Clearly, each subsystem can be influenced by a) the behaviour of the residents, b) water-using technologies and fittings, c) physical environments, d) plumbing configurations, e) building design and associated losses or gains, and f) water heating systems and energy sources. In combination, this diversity demands the systematic assessment of a wide range of parameters in order to thoroughly understand water-related energy use and greenhouse gas emissions.

According to this approach, the equations can be classified as follows:

i) "Demand" equations: (see Appendix A for the example of showers) 
The water demand to provide the service required by the residents is formulated as a function of the parameters describing the amount per day per person or household (split into sub-parameters such as amount per service, frequency of service) and the temperature of the water. The corresponding energy demand is simply calculated from the calorimetric equation for water.

ii) "Supply" equation:

The supply of water and energy is exactly the sum of the demands by the individual subsystems.

iii) "Loss" equation: (see Appendix B)

Physical equations are used for the energy loss in storage and pipes.

In mathematical terms, this set of equations is an appropriate parameterisation of the water, related energy, $\mathrm{CO}_{2-}$ equivalent and cost flows. The parameters represent either the behaviour of the residents (such as shower duration, frequency or temperature), the technical state of the water and energy system (such as heat loss coefficients) or environmental conditions (such as cold-water temperature). The selected approach is a stationary one, since we are interested in daily flows averaged over one year or one season. A dynamic approach would be required to simulate the time when water and energy are needed for the different household activities, but that is not the focus of this study.

Some water use was modelled as being directly proportional to household occupancy numbers, e.g. showering, bathing and teeth cleaning, whereas other water uses were considered to be "collective" or better characterised at household level. Examples include the number of cleaning events, the number of dishwasher or washing machine cycles, lawn watering or swimming pool filling. We adopted this approach because it identifies underlying system drivers and enables detailed changes in policy, technology, environment or behaviour to be analysed.

The washing machine subsystem was considered in particular detail because it had been identified as having significant water and energy use and was recommended for detailed analysis [10]. This system was characterised by (i) technology type (front or top-loading), (ii) number of cycles per day, (iii) cycle temperature, (iv) cycle water volume (v) and cycle mechanical/pumping energy use. Washing machines and dishwashers required case-specific demand equations to identify if the machine was plumbed to cold water only, or to both hot and cold water. In the latter case, the appliance itself uses less energy because it draws on the hot water system. In the former case, the operational energy is much higher and includes the heating of water by electricity within the appliance.

The model was structured to accommodate households which use instantaneous hot water systems as well as storage heaters to enable better characterisation of losses. Because some household functions (e.g. cooking) draw on both electricity and gas energy sources, a parameter was included to identify the relative proportion or "split" between these two. This enabled more accurate characterisation of total household gas and electricity use, which could then be compared with household records.

As already emphasised in Section 2.1, the model approach is general in the sense that it applies to the most common types of households. The model for the different household types is the same, only the set of parameters changes across different household types. This was the challenge for the development of the model, and led to a large set of parameters.

The model was implemented in the simulation program SIMBOX [23]. A Newton-Raphson iteration algorithm was used to solve the equations.

\section{Data collection and calibration for the case of the "Milton Household"}

In this study the model will be calibrated for a specific household, known as the "Milton household". The procedure would be the same for a different type of household.

\subsection{Data collection}

Parameters were characterised according to the best available information for a specific household in Milton, Brisbane. A period of relatively uniform water use (2007-2009) was selected (Figure. 2). Level 2-6 water restrictions were in place in Brisbane during this time. At Level 2, most outdoor water use (e.g. irrigation) was banned. At Level 5, residents were encouraged to reduce their use to $140 \mathrm{l} / \mathrm{cap} \cdot \mathrm{d}$. 


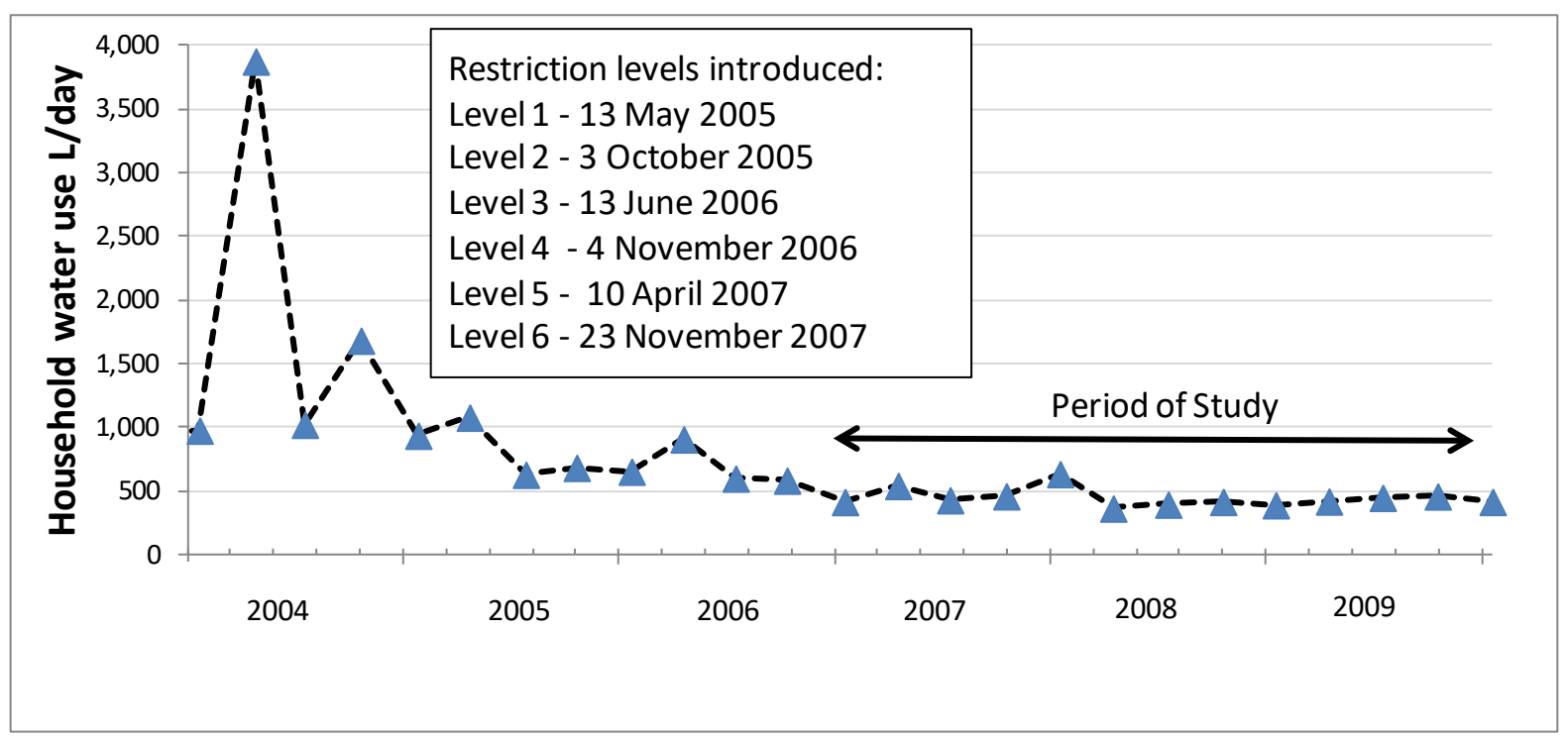

Figure 2: Water use in the household studied. A new water meter was installed in January 2003.

The calibrated parameter values describe an "average day". In this context, this means that the water and energy use over long periods (a month to a year) is divided by the numbers of days in the period. To determine these parameter values required accounting for "average" behaviour and conditions over the three years, and representing this as a daily value. We took this approach because long-term trends were more important than day-to-day changes for our purpose. However, day-to-day changes are addressed by the variability from day to day (see below). We used time-series data for parameters such as cold-water temperature, number of showers per day and number of washing machine cycles per day. In the first case, these time series were available from the bulk water supplier (SEQ Water). In the latter case, they were based on information such as "how many warm front cycles per week" and "on which days per week was the front loader used". For data where no time series were available such as the shower flowrate, average values were estimated as described below.

Two adults and two children (aged 6-10) occupied the typical "Queenslander" five-bedroom house. Periods during which household members were absent or visitors were staying were accounted for in the total mean population of adults and children. The two-storey house (longitude: 153.03 degrees East; latitude: 27.48 degrees South, elevation: $15 \mathrm{~m}$ ) experiences a subtropical climate with an annual mean of $21.3+/-3.6{ }^{\circ} \mathrm{C}$ and a mean monthly minimum of 15.5 and maximum of $25.6{ }^{\circ} \mathrm{C}$.

Household members were interviewed to determine usage patterns and behaviours. Repeated measurements were performed for the shower and bath temperatures of adults and children, washing of dishes by hand and shaving water (Table 2). Appliance efficiency data was recorded from manuals or similar appliance data available on-line. Appliance plumbing to either the cold or both hot and cold water supply was confirmed by inspection. The natural gas hot-water storage was located outside. The front-loading washing machine and dishwasher are both plumbed to cold water only, and were 7 and 12 years old respectively at the start of the period.

Natural gas $\left(37.7 \mathrm{MJ} / \mathrm{m}^{3}\right)$ is used in a cooker top. A small gas heater is used for a total of approximately $40 \mathrm{hrs}$ per year during winter. Electricity from coal-fired plants meets all other energy demands including microwave and oven cooking, air heating and cooling. The household has no pool, spa, aquarium, or water-chilling devices.

Literature values are relied on for the relatively small number of parameters that could not be determined using the above measures. For example, carbon dioxide equivalents were determined on the basis of current rates for

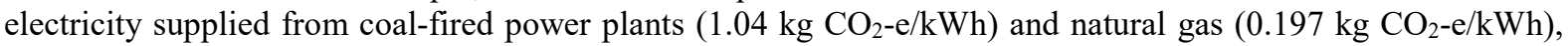
which are the average estimates in Queensland for the full fuel cycle [24].

The costs for water, electricity and gas were calculated according to the current tariff in Brisbane as shown in Table 1. In principle, the stepped tariff for gas is calculated quarterly. For reasons of simplicity we converted it to an annual tariff.

Table 1: Costs for Water, Gas and Electricity for Residential use in Brisbane, Australia. 


\begin{tabular}{|l|l|l|l|l|l|}
\hline & Fixed costs & Step 1 & Step 2 & Step 3 & Reference \\
\hline Water & $155 \$ / \mathrm{y}$ & $0-255 \mathrm{~m}^{3} / \mathrm{y}$ & $255-310 \mathrm{~m}^{3} / \mathrm{y}$ & $>310 \mathrm{~m}^{3} / \mathrm{y}$ & {$[25]$} \\
& & $0.62 \$ / \mathrm{m}^{3}$ & $0.66 \$ / \mathrm{m}^{3}$ & $1.17 \$ / \mathrm{m}^{3}$ & \\
\hline Gas* & $186 \$ / \mathrm{y}$ & $0-20,278 \mathrm{kWh} / \mathrm{y}$ & $>20,278 \mathrm{kWh}$ & - & {$[26]$} \\
& & $0.083 \$ / \mathrm{kWh}$ & $0.074 \$ / \mathrm{kWh}$ & & \\
\hline Electricity* & $90 \$ / \mathrm{y}$ & $0.194 \$ \mathrm{kWh}$ & - & - & {$[27]$} \\
\hline
\end{tabular}

*Excluding the 10\% Goods and Services Tax (GST).

Note that in Australia the specific costs for water increase the more you use, in contrast to gas use. Electricity costs per $k$ Wh are not use-dependent.

\subsection{Uncertainties of the data}

As already mentioned above, the parameter values are daily averages. Nevertheless we calculate the uncertainty for an "average day" as well as for a "single day". According to their behaviour as a function of time, the parameters can be classified into three groups. The first group are parameters which are constant over time such as heat coefficients, radius and length of hot water pipes etc. The second group are parameters which fluctuate randomly around their average such as numbers of showers per day or loads of clothes washes per day. The third group are parameters which fluctuate around a function with a seasonal pattern such as the cold-water temperature.

To characterise the uncertainty of the parameters, we calculated or estimated the standard deviation (STDV), which is the square root of the variance. In the following, we call the STDV of an average day "STDV-averageday" and the STDV of a single day "STDV-single-day". The first quantity characterises the uncertainty of the annually averaged day and the second the uncertainty of a single day. As is well known from basic statistics, the STDV-average-day is the STDV-single-day divided by $\sqrt{N_{\text {size }}}$, where $N_{\text {size }}$ is the number of data points (see Appendix C). Therefore for parameters of Group 1, where only one or a few data points are available, the STDV-average day and the STDV-single-day are identical. For parameters of Groups 2 and 3 however, where time series of at least a year are available, the STDV-average-day is at least $\sqrt{365}$ times smaller than the STDVsingle-day. The reason for this is that for parameters in Group 2 the STDV-single-day represents the variability from day to day, which is "smoothed out" in the STDV-average -day by the factor $\sqrt{365}$ (see Appendix C). For parameters of Group 3, the STDV-single-day is in a good approximation of the superposition of the variability from day to day and the "seasonal variability" (see Appendix C).

Where data was available, standard deviations were calculated to obtain an estimate. In other cases, standard deviations were estimated after discussions among the authors based on their knowledge of the household, its occupants, technologies and prevailing conditions. Estimates for appliances considered the performance range of similar technologies of similar ages. Maximum and minimum values were estimated by considering typical extremes averaged over a large sample. A conservative approach was taken, so if the uncertainty estimate (deviation and upper and lower bounds) was questioned, it was broadened until better information became available.

\subsection{Probability distribution of the parameters}

Normal distributions were used for parameters with fluctuations such as indoor and outdoor temperatures or household occupancy numbers. Truncated normal distributions were used for fluctuating parameters whose lower and upper bounds were known, such as the temperature of the cold and hot water, and heat coefficients.

Log-normal and truncated log-normal distributions are used for parameters which are known to show an asymmetrical distribution towards higher values. Examples are the number of washes per household and day or the duration of cooling. Finally, uniform distributions are used for parameters which show a uniform probability within a certain range and zero outside it, such as the number of stand times in hot-water pipes. For uniform distributions, it can be shown that the minimum / maximum boundaries depend as follows on the mean and STDV: $X_{\min }=$ Mean $-\sqrt{3} * S T D V, X_{\max }=$ Mean $+\sqrt{3} * S T D V$.

\subsection{Simulations of current state}

The model equations were solved for the parameter set described above. Water, electricity and natural gas for the house considered were obtained from the local water and energy providers. This data served to validate the model. The results of the data collection and calibration are presented in Table 2 for all 132 parameters used to characterise the stationary model that was developed. Besides the average values, the standard deviation "STDV-average-day" and "STDV-single-day", the type of distribution, and for truncated distributions the lower and upper boundaries, are also shown. 
Table 2: Calibrated parameters for the household. The table shows the distributions, means, STDV-average-day, STDV-single-day, lower and upper boundaries for truncated distributions, potential and realistic values for scenarios and the data source. Parameters marked with a "T" (red shaded) are "technical", "B" (blue shaded) are behavioural and "TB" are "technical with behavioural assistance" (green shaded). The terms "technical" and "behavioural" parameters are explained below in the scenario analysis section.

\begin{tabular}{|c|c|c|c|c|c|c|c|c|c|c|c|}
\hline No. & Unit & Description & \begin{tabular}{|l|}
$\begin{array}{l}\text { Probability } \\
\text { distribu- } \\
\text { tion }\end{array}$ \\
\end{tabular} & Mean & \begin{tabular}{|l|} 
STDV- \\
average- \\
day
\end{tabular} & $\begin{array}{l}\text { STDV- } \\
\text { single-day }\end{array}$ & \begin{tabular}{|l|} 
Lower \\
boundar \\
y (trunc) \\
\end{tabular} & \begin{tabular}{|l|} 
Upper \\
boundar \\
y (trunc) \\
\end{tabular} & \begin{tabular}{|l|} 
P Value \\
Potential
\end{tabular} & \begin{tabular}{|l|} 
P Value \\
Realistic
\end{tabular} & Data source and notes \\
\hline & \multicolumn{3}{|c|}{ Parameters for the household } & & & & & & & & \\
\hline 1 & {$[-]$} & $\begin{array}{l}\begin{array}{l}\text { Number of adults per } \\
\text { household }\end{array} \\
\end{array}$ & tnormal & 1.92 & 0.03 & 0.61 & 0 & 6 & 1.92 & 1.92 & $\begin{array}{l}\text { Survey, includes guests and } \\
\text { absences. }\end{array}$ \\
\hline 2 & {$[-]$} & $\begin{array}{l}\text { Number of children per } \\
\text { household }\end{array}$ & tnormal & 1.93 & 0.03 & 0.58 & 0 & 6 & 1.93 & 1.93 & $\begin{array}{l}\text { Survey, includes guests and } \\
\text { absences. }\end{array}$ \\
\hline 3 & {$\left[{ }^{\circ} \mathrm{C}\right]$} & Temperature cold water & tnormal & 21.3 & 0.2 & 3.6 & 15.5 & 25.6 & 21.3 & 21.3 & {$[28]$} \\
\hline 4 & {$\left[{ }^{\circ} \mathrm{C}\right]$} & $\begin{array}{l}\text { Temperature hot water at } \\
\text { HWS }\end{array}$ & tnormal & 55 & 5 & 5 & 45 & 65 & 55 & 55 & Measured \\
\hline 5 & {$\left[{ }^{\circ} \mathrm{C}\right]$} & Average indoor temperature & normal & 25 & 3 & 3 & & & 25 & 25 & Measured \\
\hline 6 & {$\left[{ }^{\circ} \mathrm{C}\right]$} & $\begin{array}{l}\text { Ambient air temperature at } \\
\text { HWS storage }\end{array}$ & normal & 21.3 & 0.13 & 3.9 & & & 21.3 & 21.3 & {$[28],[29]$} \\
\hline 7 & {$[\mathrm{~m}]$} & $\begin{array}{l}\text { Ave. length of wastewater } \\
\text { pipes }\end{array}$ & tnormal & 5 & 3 & 3 & 3 & 12 & 5 & 5 & Estimate \\
\hline 8 & {$[\mathrm{~m} / \mathrm{s}]$} & Velocity of wastewater & tnormal & 0.1 & 0.05 & 0.05 & 0.05 & 0.3 & 0.1 & 0.1 & $\begin{array}{l}\text { Estimate based on radius }(\mathrm{P} 13) \\
\text { and flow of } 30 \mathrm{~L} / \mathrm{min} \text {. }\end{array}$ \\
\hline 9 & {$[\mathrm{~m}]$} & Radius of wastewater pipe & tnormal & 0.045 & 0.005 & 0.005 & 0.03 & 0.06 & 0.045 & 0.045 & Estimate \\
\hline 10 & \begin{tabular}{|l}
$\mathrm{W} /\left(\mathrm{m}^{\wedge} 2\right.$ \\
$\left.\left.{ }^{\circ} \mathrm{K}\right)\right]$
\end{tabular} & $\begin{array}{l}\text { Heat coefficient wastewater } \\
\text { pipe }\end{array}$ & tnormal & 2 & 1 & 1 & 0.5 & 4 & 2 & 2 & PVC, [30] \\
\hline 11 & {$[\mathrm{~m}]$} & $\begin{array}{l}\text { Ave. length of hot-water } \\
\text { pipes (storage to tap) }\end{array}$ & tnormal & 7 & 2 & 2 & 2 & 10 & 7 & 7 & Estimate \\
\hline 12 & {$[\mathrm{~m} / \mathrm{s}]$} & Velocity of hot water & tnormal & 2.3 & 0.5 & 0.5 & 0.5 & 3 & 2.3 & 2.3 & $\begin{array}{l}\text { Estimate based on radius (P13) } \\
\text { and flow of } 8 \mathrm{~L} / \mathrm{min} \text { [31] }\end{array}$ \\
\hline 13 & {$[\mathrm{~m}]$} & Radius of hot-water pipe & tnormal & 0.005 & 0.002 & 0.002 & 0.003 & 0.006 & 0.005 & 0.005 & Rheem Stellar Manual 850330 \\
\hline $14-\mathrm{T}$ & $\begin{array}{l}{\left[\mathrm{W} /\left(\mathrm{m}^{\wedge} 2\right.\right.} \\
\left.\left.{ }^{\circ} \mathrm{K}\right)\right]\end{array}$ & $\begin{array}{l}\text { Heat coefficient of hot-water } \\
\text { pipe }\end{array}$ & tnormal & 2 & 1 & 1 & 0.5 & 5 & 0 & 0.2 & $\begin{array}{l}\text { Estimate using [30] for copper } \\
\text { pipe through air. }\end{array}$ \\
\hline $15-\mathrm{T}$ & $\begin{array}{l}{\left[\mathrm{W} /\left(\mathrm{m}^{\wedge} 2\right.\right.} \\
\left.\left.{ }^{\circ} \mathrm{K}\right)\right]\end{array}$ & $\begin{array}{l}\text { Heat coefficient of hot - } \\
\text { water storage }\end{array}$ & tnormal & 0.5 & 0.5 & 0.5 & 0.2 & 1.5 & 0 & 0.1 & Estimate. \\
\hline 16 & {$\left[\mathrm{~m}^{\wedge} 2\right]$} & $\begin{array}{l}\text { Surface of hot water } \\
\text { storage }\end{array}$ & tnormal & 3.04 & 0.304 & 0.304 & 1 & 4 & 3.04 & 3.04 & Rheem Stellar Manual 850330 \\
\hline 17 & {$[-]$} & $\begin{array}{l}\text { Split of hot water system: } \\
\text { share of gas use }\end{array}$ & uniform & 1 & 0 & 0 & & & 1 & 1 & Gas system. \\
\hline 18 & {$[-]$} & $\begin{array}{l}\text { Number of stand times in } \\
\text { hot-water pipes }\end{array}$ & uniform & 3 & 1 & 1 & & & 3 & 3 & \\
\hline 19 & {$[\mathrm{~m}]$} & Thickness of hot-water pipe & tnormal & 0.001 & 0.0001 & 0.0001 & 0.0005 & 0.002 & 0.001 & 0.001 & \\
\hline \multirow[t]{2}{*}{$20-\mathrm{T}$} & {$[-]$} & $\begin{array}{l}\text { Switch: hws standard(0)/ } \\
\text { solar heat (1) }\end{array}$ & uniform & 0 & 0 & 0 & & & 1 & 1 & \\
\hline & \multicolumn{3}{|c|}{ Parameters for showers } & & & & & & & & \\
\hline $21-B$ & [min] & $\begin{array}{l}\text { Flow duration per shower } \\
\text { for adults }\end{array}$ & tnormal & 4 & 0.28 & 1.3 & 1 & 5.5 & 2 & 3 & $\begin{array}{l}\text { Estimated based on } \\
\text { measurements }\end{array}$ \\
\hline 22-TB & {$[1 / \mathrm{min}]$} & $\begin{array}{l}\text { Flowrate per showers for } \\
\text { adults }\end{array}$ & tnormal & 11 & 2 & 2 & 3 & 25 & 4 & 6 & $\begin{array}{l}\text { Estimated based on } \\
\text { measurements. }\end{array}$ \\
\hline $23-B$ & {$[-]$} & $\begin{array}{l}\text { Number of showers per } \\
\text { adult per day }\end{array}$ & tnormal & 1.5 & 0.03 & 0.5 & 1 & 2 & 0.071 & 0.643 & Counted \\
\hline $24-\mathrm{B}$ & {$\left[{ }^{\circ} \mathrm{C}\right]$} & \begin{tabular}{|l|} 
Temperature of showers for \\
adults
\end{tabular} & tnormal & 41 & 2 & 2 & 30 & 45 & 35 & 38 & Measured \\
\hline $25-B$ & [min] & $\begin{array}{l}\text { Flow duration per shower } \\
\text { for child }\end{array}$ & tnormal & 5.5 & 0.6 & 1.65 & 1 & 8 & 2 & 3 & $\begin{array}{l}\text { Estimated based on } \\
\text { measurements }\end{array}$ \\
\hline 26-TB & {$[1 / \mathrm{min}]$} & $\begin{array}{l}\text { Flowrate per showers for } \\
\text { child }\end{array}$ & tnormal & 9.5 & 1 & 1 & 7 & 12 & 4 & 6 & $\begin{array}{l}\text { Estimated based on } \\
\text { measurements. }\end{array}$ \\
\hline $27-B$ & {$[-]$} & $\begin{array}{l}\text { Number of showers per } \\
\text { child per day }\end{array}$ & tnormal & 0.21 & 0.02 & 0.41 & 0 & 2 & 0.071 & 0.071 & Counted \\
\hline $28-B$ & {$\left[{ }^{\circ} \mathrm{C}\right]$} & $\begin{array}{l}\text { Temperature of showers for } \\
\text { child }\end{array}$ & tnormal & 38 & 2 & 2 & 25 & 42 & 34 & 35 & Measured \\
\hline 29 & {$[-]$} & $\begin{array}{l}\text { Fraction of instantaneous } \\
\text { shower heating }\end{array}$ & uniform & 0 & 0 & 0 & & & 0 & 0 & Not relevant to this household \\
\hline \multirow[t]{2}{*}{30} & {$[-]$} & $\begin{array}{l}\text { Split of instant. Shower: } \\
\text { share of gas use }\end{array}$ & uniform & 1 & 0 & 0 & & & 1 & 1 & Not relevant to this household \\
\hline & \multicolumn{2}{|c|}{ Parameters for bath } & & & & & & & & & \\
\hline $31-B$ & {$[1]$} & Volume per bath per adult & tnormal & 50 & 7.5 & 20 & 20 & 120 & 20 & 30 & Measured \\
\hline 32-B & {$[-]$} & $\begin{array}{l}\text { Number of baths per adult } \\
\text { per day }\end{array}$ & tnormal & 0.18 & 0.02 & 0.38 & 0 & 0.4 & 0.571 & 0.071 & Measured \\
\hline 33-B & {$\left[{ }^{\circ} \mathrm{C}\right]$} & $\begin{array}{l}\text { Temperature of baths for } \\
\text { adults }\end{array}$ & tnormal & 41 & 2 & 2 & 37 & 45 & 39 & 40 & Measured \\
\hline $34-\mathrm{B}$ & {$[1]$} & Volume per bath per child & tnormal & 37 & 5.55 & 10 & 20 & 90 & 20 & 30 & Measured \\
\hline $35-\mathrm{B}$ & {$[-]$} & $\begin{array}{l}\text { Number of baths per child } \\
\text { per day }\end{array}$ & tnormal & 0.89 & 0.016 & 0.32 & $\overline{0.5}$ & 1.2 & 0.571 & 0.79 & Estimated \\
\hline 36-B & {$\left[{ }^{\circ} \mathrm{C}\right]$} & $\begin{array}{l}\text { Temperature of baths for } \\
\text { child }\end{array}$ & tnormal & 38 & 3 & 3 & 27 & 42 & 36 & 37 & Measured \\
\hline 37 & {$[-]$} & $\begin{array}{l}\text { Fraction of instantaneous } \\
\text { bath heating }\end{array}$ & uniform & 0 & 0 & 0 & & & 0 & 0 & Not relevant to this household \\
\hline 38 & {$[-]$} & $\begin{array}{l}\text { Split of instant. bath share } \\
\text { of gas use }\end{array}$ & uniform & 1 & 0 & 0 & & & 1 & 1 & Not relevant to this household \\
\hline
\end{tabular}




\begin{tabular}{|c|c|c|c|c|c|c|c|c|c|c|c|}
\hline \multirow{2}{*}{\begin{tabular}{|l|} 
\\
$39-B$ \\
\end{tabular}} & \multicolumn{2}{|c|}{ Parameters for clothes wash } & \multirow[b]{2}{*}{ uniform } & \multirow[b]{2}{*}{0} & \multirow[b]{2}{*}{0} & \multirow[b]{2}{*}{0} & & & \multirow[b]{2}{*}{0} & \multirow[b]{2}{*}{0} & \multirow[b]{2}{*}{ Not relevant to this household } \\
\hline & {$[-]$} & $\begin{array}{l}\text { Number cycles cold top per } \\
\text { day }\end{array}$ & & & & & & & & & \\
\hline $40-B$ & {$[-]$} & $\begin{array}{l}\text { Number cycles warm top } \\
\text { per day }\end{array}$ & uniform & 0 & 0 & 0 & & & 0 & 0 & Not relevant to this household \\
\hline $41-B$ & {$[-]$} & $\begin{array}{l}\text { Number cycles hot top per } \\
\text { day }\end{array}$ & uniform & 0 & 0 & 0 & & & 0 & 0 & Not relevant to this household \\
\hline 42-B & {$[-]$} & $\begin{array}{l}\text { Number cycles cold front } \\
\text { per day }\end{array}$ & uniform & 0 & 0 & 0 & & & 0 & 0 & Not relevant to this household \\
\hline 43-B & {$[-]$} & $\begin{array}{l}\text { Number cycles warm front } \\
\text { per day }\end{array}$ & tnormal & 0.93 & 0.07 & 1.33 & 0 & 1.43 & 0.5 & 0.643 & Estimated \\
\hline 44-B & {$[-]$} & $\begin{array}{l}\text { Number cycles hot front per } \\
\text { day }\end{array}$ & tnormal & 0.066 & 0.013 & 0.25 & 0.05 & 0.4 & 0.022 & 0.033 & Estimated \\
\hline 45-T & {$[1]$} & Volume per cycle cold top & uniform & 0 & 0 & 0 & & & 0 & 0 & Not relevant to this household \\
\hline 46- $\mathrm{T}$ & {$[$ [l] } & Volume per cycle warm top & uniform & 0 & 0 & 0 & & & 0 & 0 & Not relevant to this household \\
\hline $47-\mathrm{T}$ & {$[1]$} & Volume per cycle hot top & uniform & 0 & 0 & 0 & & & 0 & 0 & Not relevant to this household \\
\hline 48-T & {$[1]$} & Volume per cycle cold front & tnormal & 62 & 9.3 & 10 & 50 & 90 & 40 & 40 & [32], estimate \\
\hline 49-T & {$[1]$} & \begin{tabular}{|l|}
$\begin{array}{l}\text { Volume per cycle warm } \\
\text { front }\end{array}$ \\
\end{tabular} & tnormal & 62 & 9.3 & 10 & 50 & 90 & 52 & 52 & [32], estimate \\
\hline 50- & {$[1]$} & Volume per cycle hot front & tnormal & 62 & 9.3 & 10 & 50 & 90 & 47 & 47 & [32], estimate \\
\hline $51-\mathrm{T}$ & {$[\mathrm{kWh}]$} & $\begin{array}{l}\text { Energy per cycle cold top } \\
\text { (excl. water heating) }\end{array}$ & uniform & 0 & 0 & 0 & & & 0 & 0 & [10] \\
\hline 52- $\mathrm{T}$ & {$[\mathrm{kWh}]$} & $\begin{array}{l}\text { Energy per cycle warm top } \\
\text { (excl. water heating) }\end{array}$ & uniform & 0 & 0 & 0 & & & 0 & 0 & [10] \\
\hline 53- $\mathrm{T}$ & {$[\mathrm{kWh}]$} & $\begin{array}{l}\text { Energy per cycle hot top } \\
\text { (excl. water heating) }\end{array}$ & uniform & 0 & 0 & 0 & & & 0 & 0 & [10] \\
\hline 54- & [kWh] & $\begin{array}{l}\text { Energy per cycle cold front } \\
\text { (excl. water heating) }\end{array}$ & tnormal & 0.35 & 0.0525 & 0.1 & 0.1 & 0.6 & 0.2 & 0.225 & [32], estimate \\
\hline 55- $\mathrm{T}$ & {$[\mathrm{kWh}]$} & $\begin{array}{l}\text { Energy per cycle warm front } \\
\text { (excl. water heating) }\end{array}$ & tnormal & 0.35 & 0.0525 & 0.1 & 0.1 & 0.6 & 0.2 & 0.225 & [32], estimate \\
\hline 56- & {$[\mathrm{kWh}]$} & $\begin{array}{l}\text { Energy per cycle hot front } \\
\text { (excl. water heating) }\end{array}$ & tnormal & 0.35 & 0.0525 & 0.1 & 0.1 & 0.6 & 0.2 & 0.225 & [32], estimate \\
\hline $57-B$ & {$\left[{ }^{\circ} \mathrm{C}\right]$} & Temperature cold cycle top & uniform & 0 & 0 & 0 & & & 0 & $\overline{0}$ & [10] \\
\hline $58-B$ & {$\left[{ }^{\circ} \mathrm{C}\right]$} & $\begin{array}{l}\text { Temperature warm cycle } \\
\text { top }\end{array}$ & uniform & 0 & 0 & 0 & & & 0 & 0 & [10] \\
\hline $59-B$ & {$\left[{ }^{\circ} \mathrm{C}\right]$} & Temperature hot cycle top & uniform & 0 & 0 & 0 & & & 0 & 0 & [10] \\
\hline 60-B & {$\left[{ }^{\circ} \mathrm{C}\right]$} & $\mid$\begin{tabular}{|l} 
Temperature cold cycle \\
front
\end{tabular} & normal & 30 & 3 & 3 & & & 25 & 25 & Program value \\
\hline $61-B$ & {$\left[{ }^{\circ} \mathrm{C}\right]$} & $\begin{array}{l}\begin{array}{l}\text { Temperature warm cycle } \\
\text { front }\end{array} \\
\text { frot }\end{array}$ & normal & 40 & 3 & 3 & & & 35 & 40 & Program value \\
\hline $62-B$ & {$\left[{ }^{\circ} \mathrm{C}\right]$} & Temperature hot cycle front & tnormal & 65 & 5 & 5 & 50 & 95 & 55 & 65 & Program value \\
\hline 63-T & {$[\mathrm{min}]$} & Duration average cycle top & uniform & 0 & 0 & 0 & & & 0 & 0 & [10] \\
\hline 64-T & {$[\mathrm{min}]$} & $\begin{array}{l}\text { Duration average cycle } \\
\text { front }\end{array}$ & tnormal & 60 & 9 & 20 & 20 & 90 & 60 & 60 & [32] \\
\hline $65-\mathrm{T}$ & {$[\mathrm{W}]$} & Standby energy top & uniform & 0 & 0 & 0 & & & 0 & 0 & [33] \\
\hline 66-T & [W] & Standby energy front & tnormal & 4 & 1 & 1 & 1 & 8 & 0 & 0 & [33] \\
\hline \multirow[t]{2}{*}{ 67- } & {$[-]$} & $\begin{array}{l}\begin{array}{l}\text { Connected to hot+cold (0) } \\
\text { or only cold (1) water } \\
\text { (SWITCH) }\end{array} \\
\end{array}$ & uniform & 1 & 0 & 0 & & & 1 & 1 & Only cold water connection \\
\hline & \multicolumn{2}{|c|}{ Parameters for taps } & & & & & & & & & \\
\hline $68-B$ & {$[-]$} & $\begin{array}{l}\text { Number hand wash per } \\
\text { person per day }\end{array}$ & tnormal & 12 & 0.157 & 3 & 4 & 18 & 9 & 11 & Estimate \\
\hline 69-ТВ & {$[1]$} & Volume per hand wash & tnormal & 0.83 & 0.125 & 0.3 & 0.2 & 2 & 0.1 & 0.3 & Estimate \\
\hline $70-B$ & {$\left[{ }^{\circ} \mathrm{C}\right]$} & Temperature hand wash & tnormal & 32 & 5 & 5 & 20 & 42 & 21.3 & 21.3 & Estimate \\
\hline $71-B$ & {$[-]$} & $\begin{array}{l}\text { Number teeth brush per } \\
\text { person per day }\end{array}$ & tnormal & 2 & 0.05 & 0.05 & 0 & 3 & 2 & 2 & Estimate \\
\hline 72-TB & {$[1]$} & Volume teeth brush & tlognormal & 0.3 & 0.045 & 0.1 & 0 & 2 & 0.05 & 0.1 & Estimate \\
\hline 73-B & {$\left[{ }^{\circ} \mathrm{C}\right]$} & Temperature teeth brush & tnormal & 27 & 2 & 2 & 20 & 32 & 21.3 & 21.3 & Estimate \\
\hline 74-B & {$[-]$} & $\begin{array}{l}\begin{array}{l}\text { Number shave per adult per } \\
\text { day }\end{array} \\
\end{array}$ & tnormal & 0.5 & 0.01 & 0.18 & 0 & 1 & 0 & 0.4 & Estimate \\
\hline $75-B$ & {$[1]$} & Volume per shave & tnormal & 2.5 & 0.375 & 1 & 1.5 & 5 & 0.1 & 1 & Measured \\
\hline $76-B$ & {$\left[{ }^{\circ} \mathrm{C}\right]$} & Temperature shave & tnormal & 45 & 2 & 2 & 40 & 55 & 21.3 & 35 & Measured \\
\hline $77-B$ & {$[-]$} & $\begin{array}{l}\text { Number dish wash (by } \\
\text { hand) per hh per day }\end{array}$ & tnormal & 2 & 0.1 & 0.5 & 0 & 4 & 2 & 2 & Estimate \\
\hline 78-B & {$[1]$} & $\begin{array}{l}\text { Volume dish wash (by } \\
\text { hand) }\end{array}$ & tnormal & 7 & 1 & 1 & 5 & 12 & 4 & 5.5 & Manual \\
\hline 79-B & {$\left[{ }^{\circ} \mathrm{C}\right]$} & $\begin{array}{l}\text { Temperature dish wash (by } \\
\text { hand) }\end{array}$ & tnormal & 46 & 4 & 4 & 42 & 60 & 39 & 43 & Manual \\
\hline $80-B$ & {$[-]$} & $\begin{array}{l}\text { Number clothes wash (by } \\
\text { hand) per hh per day }\end{array}$ & tnormal & 0.033 & 0.01 & 0.18 & 0 & 0.2 & 0.005 & 0.01 & Estimate \\
\hline $81-B$ & {$[1]$} & $\begin{array}{l}\begin{array}{l}\text { Volume per clothes wash } \\
\text { (by hand) }\end{array} \\
\end{array}$ & tlognormal & 15 & 5 & 5 & 5 & 40 & 10 & 12.5 & Estimate \\
\hline $82-B$ & {$\left[{ }^{\circ} \mathrm{C}\right]$} & $\begin{array}{l}\begin{array}{l}\text { Temperature clothes wash } \\
\text { (by hand) }\end{array} \\
\text { (be) }\end{array}$ & tnormal & 35 & 5 & 5 & 25 & 45 & 25 & 25 & Estimate \\
\hline 83-B & {$[-]$} & $\begin{array}{l}\begin{array}{l}\text { Number cleaning per hh per } \\
\text { day }\end{array} \\
\text { date }\end{array}$ & |lognormal & 1 & 0.06 & 1.2 & & & 0.33 & 0.37 & Estimate \\
\hline
\end{tabular}




\begin{tabular}{|c|c|c|c|c|c|c|c|c|c|c|c|}
\hline 84-B & {$[1]$} & Volume cleaning & lognormal & 7 & 1.05 & 5 & & & 7 & 7 & Estimate \\
\hline $85-B$ & {$\left[{ }^{\circ} \mathrm{C}\right]$} & Temperature cleaning & tnormal & 47 & 5 & 5 & 35 & 65 & 40 & 45 & Estimate \\
\hline $86-B$ & {$[-]$} & $\begin{array}{l}\text { Number other use per } \\
\text { person per day }\end{array}$ & lognormal & 10 & 1.5 & 3 & & & 4 & 5 & Estimate \\
\hline 87-B & {$[1]$} & Volume other use & lognormal & 1.3 & 0.2 & 0.2 & & & 1 & 1 & Estimate \\
\hline 88-B & {$\left[{ }^{\circ} \mathrm{C}\right]$} & Temperature other use & lognormal & 30 & 5 & 5 & & & 21.3 & 21.3 & Estimate \\
\hline 89 & {$[-]$} & $\begin{array}{l}\text { Fraction of instantaneous } \\
\text { tap water heating }\end{array}$ & uniform & 0 & 0 & 0 & & & 0 & 0 & Not relevant to this household \\
\hline 90 & {$[-]$} & $\begin{array}{l}\text { Split of instant. taps share } \\
\text { of gas use }\end{array}$ & uniform & 1 & 0 & 0 & & & 1 & 1 & Not relevant to this household \\
\hline & \multicolumn{2}{|c|}{ Parameters for dishwasher } & & & & & & & & & \\
\hline $91-B$ & {$[-]$} & $\begin{array}{l}\text { Number cycles dishwasher } \\
\text { per day }\end{array}$ & tnormal & 1 & 0.02 & 0.38 & 0 & 2 & 1 & 1 & Estimate \\
\hline 92- $\mathrm{T}$ & {$[1]$} & $\begin{array}{l}\text { Volume per cycle } \\
\text { dishwasher }\end{array}$ & tnormal & 18 & 4 & 4 & 10 & 30 & 7 & 7 & $\begin{array}{l}\text { Estimate for 12-setting, } 1995 \\
\text { Blanco machine }\end{array}$ \\
\hline 93- $\mathrm{T}$ & {$[\mathrm{kWh}]$} & $\begin{array}{l}\text { Energy per cycle } \\
\text { dishwasher (excl. water } \\
\text { heating) }\end{array}$ & tlognormal & 0.33 & 0.0495 & 0.1 & 0.2 & 0.4 & 0.3 & 0.3 & $\begin{array}{l}\text { Estimate for 12-setting, } 1995 \\
\text { Blanco machine }\end{array}$ \\
\hline 94-B & {$\left[{ }^{\circ} \mathrm{C}\right]$} & $\begin{array}{l}\text { Temperature dishwasher } \\
\text { cycle }\end{array}$ & tnormal & 50 & 5 & 5 & 40 & 70 & 40 & 45 & $\begin{array}{l}\text { Estimate for 12-setting, } 1995 \\
\text { Blanco machine }\end{array}$ \\
\hline 95- & {$[\mathrm{min}]$} & $\begin{array}{l}\text { Duration average cycle } \\
\text { dishwasher }\end{array}$ & tnormal & 100 & 10 & 10 & 30 & 200 & 100 & 100 & $\begin{array}{l}\text { Estimate for 12-setting, } 1995 \\
\text { Blanco machine }\end{array}$ \\
\hline 96- $\mathrm{T}$ & [W] & Standby energy dishwasher & tnormal & 2 & 0.5 & 0.5 & 0.5 & 4 & 0 & 0 & $\begin{array}{l}\text { Estimate for 12-setting, } 1995 \\
\text { Blanco machine }\end{array}$ \\
\hline $97-\mathrm{T}$ & {$[-]$} & $\begin{array}{l}\text { Connected to hot }+ \text { cold }(0) \\
\text { or only cold (1) water } \\
\text { (SWITCH) }\end{array}$ & uniform & 1 & 0 & 1 & & & 1 & 1 & Only cold water connection \\
\hline & \multicolumn{2}{|c|}{ Parameters for outdoor use } & & & & & & & & & \\
\hline 98-B & {$[1]$} & Pool volume per day & uniform & 0 & 0 & 0 & & & 0 & 0 & Not relevant \\
\hline 99-B & [l] & Irrigation per day & tnormal & 0 & 0 & 0 & 0 & 0 & 0 & 0 & Irrigation not allowed. \\
\hline $100-B$ & [min] & $\begin{array}{l}\text { Duration pool filtration per } \\
\text { day }\end{array}$ & uniform & 0 & 0 & 0 & & & 0 & 0 & Not relevant \\
\hline $101-\mathrm{T}$ & {$[\mathrm{kW}]$} & Power of pool filter & uniform & 0 & 0 & 0 & & & 0 & 0 & Not relevant \\
\hline & \multicolumn{2}{|c|}{ Parameters for toilet flush } & & & & & & & & & \\
\hline 102-B & {$[-]$} & $\begin{array}{l}\text { Number toilet flushes per } \\
\text { person per day }\end{array}$ & tlognormal & 3.7 & 0.555 & 1 & 2 & 10 & 2 & 3.3 & [15] \\
\hline 103-TB & {$[1]$} & Volume per toilet flush & tnormal & 4.7 & 0.705 & 1 & 2 & 9 & 0.75 & 3.3 & {$[15]$} \\
\hline & \multicolumn{2}{|c|}{ Parameters for kettle boil } & & & & & & & & & \\
\hline 104-B & {$[-]$} & $\begin{array}{l}\text { Number of kettle boils per } \\
\text { person per day }\end{array}$ & tnormal & 2 & 0.3 & 1.2 & 0 & 6 & 2 & 2.5 & Estimate \\
\hline $105-\mathrm{B}$ & {$[1]$} & Volume per boil & tnormal & 1.2 & 0.18 & 0.5 & 0.5 & 1.8 & 0.5 & 1 & {$[34]$} \\
\hline & \multicolumn{2}{|c|}{ Parameters for aircon } & & & & & & & & & \\
\hline 106-T & {$[1 / \mathrm{min}]$} & Water use aircon evap. & tlognormal & 1.5 & 0.225 & 1 & 0.2 & 13 & 1.5 & 1.5 & [15] \\
\hline $107-\mathrm{B}$ & {$[\mathrm{min}]$} & Duration use aircon evap. & uniform & 0 & 0 & 0 & & & 0 & 0 & [15] \\
\hline $108-\mathrm{T}$ & [W] & Energy used aircon evap. & lognormal & 800 & 120 & 300 & & & 800 & 800 & {$[33]$} \\
\hline 109-T & {$[\mathrm{W}]$} & $\begin{array}{l}\text { Standby energy aircon } \\
\text { evap. }\end{array}$ & uniform & 0 & 0 & 0 & & & 0 & 0 & Estimate \\
\hline $110-\mathrm{B}$ & [min] & Duration use aircon rest & tnormal & 13 & 1.95 & 5 & 4 & 20 & 0 & 2 & Estimate \\
\hline $111-T$ & [W] & Energy used aircon rest & tnormal & 4500 & 675 & 1500 & 2000 & 20000 & 4500 & 4500 & [35], ductless mini system \\
\hline $112-T$ & {$[\mathrm{~W}]$} & Standby energy aircon rest & tnormal & 10 & 5 & 5 & 2 & 18 & 0 & 0 & Estimate \\
\hline & \multicolumn{2}{|c|}{ Parameters for other energy use } & & & & & & & & & \\
\hline 113-B & [min] & Duration use cooking & lognormal & 120 & 18 & 30 & & & 120 & 120 & Estimate \\
\hline $114-B$ & [W] & Energy used cooking & tnormal & 1389 & 208.35 & 300 & 500 & 2500 & 1000 & 1100 & {$[33]$} \\
\hline 115- $\mathrm{T}$ & {$[\mathrm{W}]$} & Standby energy cooking & tnormal & 5 & 2 & 2 & 1 & 10 & 0 & 0 & {$[33]$} \\
\hline $116-B$ & [min] & Duration use fridge & uniform & 1440 & 0 & 0 & & & 1440 & 1440 & Operates $24 \mathrm{hrs}$ per day \\
\hline $117-T$ & {$[\mathrm{~W}]$} & Energy used fridge & tnormal & 140 & 30 & 30 & 90 & 170 & 40 & 47 & $\begin{array}{l}\text { Estimate, } 2 \text { fridges }(600 \mathrm{~L} \text { and } \\
100 \mathrm{~L}) .[33] .\end{array}$ \\
\hline 118- $\mathrm{T}$ & {$[\mathrm{W}]$} & Standby energy fridge & uniform & 0 & 0 & 0 & & & 0 & 0 & Estimate, fridge always on \\
\hline 119-B & {$[\mathrm{min}]$} & Duration use TV & tnormal & 120 & 18 & 60 & 0 & 300 & 0 & 60 & Estimate \\
\hline $120-T$ & {$[\mathrm{~W}]$} & Energy used TV & lognormal & 150 & 22.5 & 50 & & & 67 & 115 & {$[33]$} \\
\hline $121-\mathrm{T}$ & {$[\mathrm{W}]$} & Standby energy TV & lognormal & 3.4 & 1 & 1 & & & 0 & 0 & Estimate \\
\hline $122-B$ & [min] & Duration use light & tnormal & 1800 & 270 & 750 & 200 & 5000 & 1800 & 1800 & Estimate \\
\hline 123-T & {$[\mathrm{W}]$} & Energy used light & lognormal & 30 & 4.5 & 10 & & & 20 & 30 & $\begin{array}{l}\text { Mix of } 40-60 \mathrm{w} \text { and compact } \\
\text { fluorescent lights. }\end{array}$ \\
\hline & {$[\mathrm{W}]$} & Standby energy light & uniform & 0 & 0 & 0 & & & 0 & 0 & Not relevant \\
\hline
\end{tabular}




\begin{tabular}{|c|l|l|l|c|c|c|c|c|c|c|c|}
\hline $124-\mathrm{T}$ & & & & & & & & \\
\hline $125-\mathrm{B}$ & {$[\mathrm{min}]$} & Duration use PC & lognormal & 171 & 25.65 & 60 & & & 60 & 171 & Estimate. Two laptops. \\
\hline $126-\mathrm{T}$ & {$[\mathrm{W}]$} & Energy used PC & lognormal & 250 & 37.5 & 100 & & & 30 & 130 & {$[36]$} \\
\hline $127-\mathrm{T}$ & {$[\mathrm{W}]$} & Standby energy PC & lognormal & 10 & 3 & 3 & & & 0 & 0 & {$[33]$} \\
\hline $128-\mathrm{B}$ & {$[\mathrm{min}]$} & Duration use heating & lognormal & 3.9 & 0.585 & 2 & & & 0 & 0 & Estimate \\
\hline $129-\mathrm{T}$ & {$[\mathrm{W}]$} & Energy used heating & lognormal & 2400 & 360 & 1000 & & & 2400 & 2400 & {$[33]$} \\
\hline $130-\mathrm{T}$ & {$[\mathrm{W}]$} & Standby energy heating & uniform & 0 & 0 & 0 & & & 0 & 0 & Estimate \\
\hline 131 & {$[-]$} & $\begin{array}{l}\text { Split of cooking energy: } \\
\text { share of gas use }\end{array}$ & tnormal & 0.5 & 0.1 & 0.1 & 0.25 & 0.75 & 0.5 & 0.5 & Estimate \\
\hline 132 & {$[-]$} & $\begin{array}{l}\text { Split of heating energy: } \\
\text { share of gas use }\end{array}$ & tnormal & 0.5 & 0.1 & 0.1 & 0.25 & 0.75 & 0.5 & 0.5 & Estimate \\
\hline
\end{tabular}

*Note for parameters P23, P32, P35 and P78 are based on samples of $N=6,7,4$ and 3 respectively. Total shower flow volume was measured 16 times for adults and 9 times for children.

Remark: Some parameters in Table 2, such as P17, P20, P29, P30, P37, P38 and P67 are switches rather than parameters in a strict mathematical sense. However, for reasons of simplicity they are included in the parameter list for the simulations. These parameters are used to distinguish between different types of appliances in the households.

\section{Results and Discussion}

4.1 Validation with data about current water, gas and electricity use and data from other studies

Table 3 shows a comparison of the simulated results with measurements and data from other studies for water, gas and electricity use. Simulated water and electricity use are in good agreement with the measured data. The simulated gas use is $30 \%$ higher than the measured use. The parameters for the shower (most important hot water consuming subsystem), such as the flowrate and duration, may have been slightly overestimated. Compared to the average Australian household, the Milton household uses significantly less water and energy, namely $50 \%$ less water and $60 \%$ less energy on a per person basis. One reason may be that the average Australian household counts 2.6 persons per household whereas the Milton one comprises four persons including two children who consume less. Another reason could be that Brisbane had stricter levels of water restrictions than many other Australian areas. The household members are also generally proactive with regard to water and energy conservation.

Table 3: Modelled and measured water, electricity and natural gas use and data from other studies. The greyshaded values represent the simulated and measured values for the Milton household.

\begin{tabular}{|c|c|c|c|c|c|}
\hline & Unit & Source & Mean & $\begin{array}{l}\text { STDV- } \\
\text { average- } \\
\text { day }\end{array}$ & Remarks \\
\hline \multirow[t]{8}{*}{ Total water use } & 1/(hh·day) & Model & 464 & 33 & Milton 4-person household \\
\hline & 1/(hh·day) & $\mathrm{QUU}^{\mathrm{a}}$ & 451 & 74 & Milton 4-person household \\
\hline & 1/(cap·day) & $\mathrm{QUU}^{\mathrm{a}}$ & 113 & 19 & Milton 4-person household \\
\hline & 1/(hh·day) & {$[10]$} & 490 & & 3-person household \\
\hline & 1/(hh·day) & $\begin{array}{l}\text { Australian } \\
\text { average [37] }\end{array}$ & 548 & & 2.6 persons per household \\
\hline & 1/(cap·day) & $\begin{array}{l}\text { Australian } \\
\text { average [37] }\end{array}$ & 203 & & \\
\hline & $\$ /($ hh.d $)$ & Model & 0.71 & 0.02 & Milton 4-person household \\
\hline & $\$ /($ hh.d $)$ & $\mathrm{QUU}^{\mathrm{b}}$ & 0.68 & 0.10 & Milton 4-person household \\
\hline \multirow[t]{8}{*}{ Total gas use } & $\mathrm{kWh} /($ hh·day) & Model & 9.1 & 2 & Milton 4-person household \\
\hline & $\mathrm{kWh} /(\mathrm{hh} \cdot$ day $)$ & $\mathrm{AGL}^{\mathrm{c}}$ & 7.4 & 2.9 & Milton 4-person household \\
\hline & $\mathrm{kWh} /(\mathrm{hh} \cdot$ day $)$ & $\mathrm{AGL}^{\mathrm{c}^{*}}$ & 7.0 & 0.15 & Milton 4-person household \\
\hline & $\mathrm{kWh} /(\mathrm{cap} \cdot$ day $)$ & $\mathrm{AGL}^{\mathrm{c}^{*}}$ & 1.8 & 0.7 & Milton 4-person household \\
\hline & $\mathrm{kWh} /(\mathrm{hh} \cdot$ day) & $\begin{array}{l}\text { Australian } \\
\text { average } \mathrm{d}[1]\end{array}$ & 17.7 & & 2.6 persons per household \\
\hline & kWh/(cap·day) & $\begin{array}{l}\text { Australian } \\
\text { average }^{\mathrm{d}}[1]\end{array}$ & 6.8 & & \\
\hline & $\$ /($ hh.d $)$ & Model & 1.36 & 0.2 & Milton 4-person household \\
\hline & $\$ /($ hh.d $)$ & $\mathrm{AGL}^{\mathrm{c}}$ & 1.13 & 0.50 & Milton 4-person household \\
\hline Total losses alone & $\mathrm{kWh} /($ hh·day) & Model $^{\mathrm{e}}$ & 1.4 & 1.3 & Milton 4-person household \\
\hline $\begin{array}{l}\text { Total electricity } \\
\text { use }\end{array}$ & $\mathrm{kWh} /($ hh·day) & Model & 12.1 & 1.0 & Milton 4-person household \\
\hline
\end{tabular}




\begin{tabular}{|c|c|c|c|c|c|}
\hline & kWh/(hh·day) & Energex $^{\mathrm{f}}$ & 12.3 & 1.2 & Milton 4-person household \\
\hline & $\mathrm{kWh} /(\mathrm{cap} \cdot$ day $)$ & Energex $^{\mathrm{f}}$ & 3.1 & 0.3 & Milton 4-person household \\
\hline & $\mathrm{kWh} /(\mathrm{hh} \cdot$ day) & $\begin{array}{l}\text { Australian } \\
\text { average [1] }\end{array}$ & 19.4 & & 2.6 persons per household \\
\hline & $\mathrm{kWh} /($ cap·day) & $\begin{array}{l}\text { Australian } \\
\text { average [1] }\end{array}$ & 7.4 & & \\
\hline & $\$ /($ hh.d) & Model & 2.59 & 0.20 & Milton 4-person household \\
\hline & $\$ /($ hh.d) & Energex ${ }^{\mathrm{g}}$ & 2.34 & 0.18 & Milton 4-person household \\
\hline $\begin{array}{l}\text { Hot water system } \\
\text { (gas) }\end{array}$ & $\mathrm{kWh} /($ hh $\cdot$ day) & Model & 7.6 & 2 & Milton 4-person household \\
\hline $\begin{array}{l}\text { Hot water system } \\
\text { gas }\end{array}$ & $\mathrm{kWh} /(\mathrm{hh} \cdot$ day) & Flower [10] & 15.5 & & 3-person household \\
\hline $\begin{array}{l}\text { Hot water system } \\
\text { electric }\end{array}$ & kWh/(hh·day) & Flower [10] & 12.6 & & 3-person household \\
\hline $\begin{array}{l}\text { Total water- } \\
\text { related } \\
\text { greenhouse gas } \\
\text { emissions }\end{array}$ & $\begin{array}{l}\mathrm{kg} \mathrm{CO}_{2}-\mathrm{e} / \\
\text { (hh.day) }\end{array}$ & Model & 5.4 & 0.5 & Milton 4-person household \\
\hline
\end{tabular}

${ }^{a}$ Data from Queensland Urban Utilities covering 12 quarters from 16/01/2007 to 16/01/2010. ${ }^{b}$ Based on 6 bills from Urban Utilities from 13/07/2007to 14/07/2009. In addition to the costs stated in Table 1, there was a "state water charge" which was not considered in the model. ${ }^{c} A G L$ data is based on 10 bills from 22/05/2007 to 9/04/2010. ${ }^{c *} A G L$ data is based on two complete years' data from 20/02/2008 to 22/02/2010. ' Data for Australian average includes LPG usage in addition to natural gas. Data based on 8,235,000 households and 21,498,500 persons. ${ }^{e}$ Includes heat losses from the (gas) hot water system and pipes. ${ }^{f}$ Energex data is from 13 records from 12/02/2007 to 9/02/2010. ${ }^{g}$ Energex financial data is based on 5 bills from 14/08/2008 to 9/02/2010.

While total water use was highly comparable to Flower's 3-person household, modelled and measured natural gas usage was approximately half the result found by Flower [10]. This is probably because shower water use in Flowers' [7] work was higher (209 1/hh.d for three people in Flower's model; 76,000 1/year). Simulated electricity and gas costs were highly comparable with results from available bills. Water-related greenhouse gas emissions accounted for about 2 tons of $\mathrm{CO}_{2}$ emissions per household and year.

\subsection{Contributions of single service subsystems}

Figure 3 shows a value-proportional water flow scheme for the cold, hot and wastewater flows for the Milton household. Of the $470 \mathrm{l} / \mathrm{hh}$ and day, 3101 are used as cold water and the rest, namely $160 \mathrm{l}$, as hot water. The dominant service subsystems in terms of wastewater flows are the shower, bath, taps, washing machine and toilet flushing. Note that the total wastewater flow is slightly lower than the total water inflow since the water uses for outdoor use, kettle and air conditioner are not directly connected to the wastewater flows. 


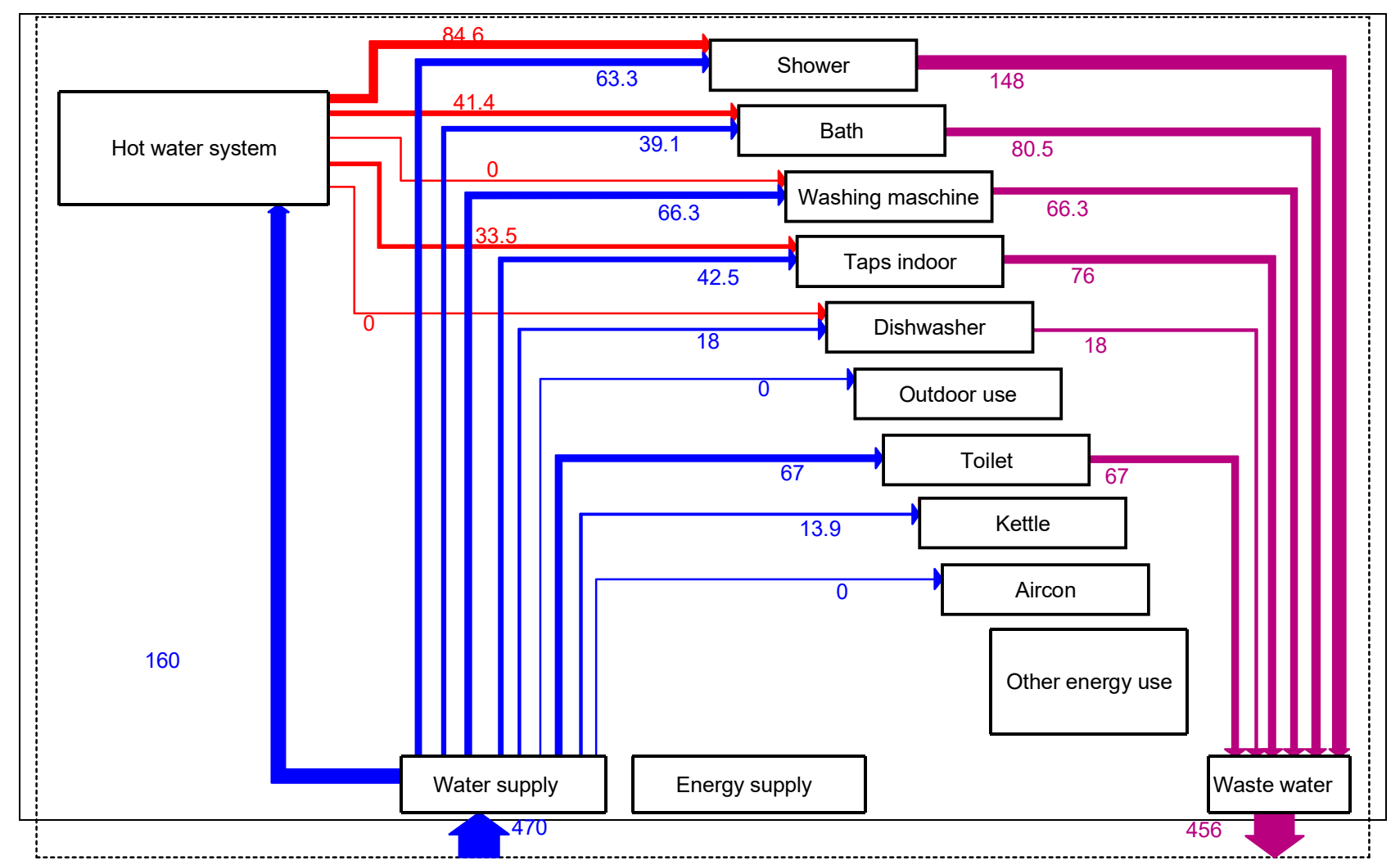

Figure 3: Value-proportional water flow scheme for the cold, hot and wastewater flows for the Milton household.

Figure 4 gives a more detailed analysis of the water flows and the connected energy flows, greenhouse gas emissions and costs including the "STDV-average-day" and "STDV-single-day".

The hierarchy in the energy flows and costs is similar to that of the water flows except that no energy is used for the toilet. The picture for greenhouse gas emissions is different, since the specific $\mathrm{CO}_{2}$ emissions per $\mathrm{kWh}$ for electricity (from coal-fired power plants) and gas differ by a factor of 5.3. The contributions of the gas-operated shower, bath and taps are consequently much lower than of the electrically operated washing machine, dishwasher and kettle. This would obviously change if power plants with lower carbon emissions were used for the electricity.

The total costs of water and energy in Fig. 4 at first sight show a similar pattern to the water flows. However, a closer look reveals that washing machines and dishwashers as well as kettles have higher costs due to a disproportionately greater use of electricity.

The water-related greenhouse gas emissions are $5.4 \mathrm{~kg} \mathrm{CO}_{2} /$ (hh and day), including losses of $0.27 \mathrm{~kg} \mathrm{CO} /(\mathrm{hh}$ and day). This corresponds well with the value of Flower [ref.], who found water-related full-fuel cycle greenhouse gas emissions of $5.56 \mathrm{~kg} \mathrm{CO}$-e/hh.d for a household using natural-gas water heating. However, unlike Flower's "average" household, in which $37 \%$ of water-related emissions were associated with showerwater use, the water-related greenhouse gas emissions from the Milton household were dominated by the use of electrical energy by the washing machine for heating water (37\%). In Flower's household, the washing machine drew hot water from the natural-gas hot-water system. Consequently, even though the two households appear similar, the sources of their water-related emissions are fundamentally different and substantially influenced by the plumbing configurations of the washing machine.

\section{Uncertainty}

The standard deviations for the daily average value (STDV-average-day) and for the single day (STDV-singleday) are shown in Fig. 4. Figure 5 presents the probability density distribution for 6 key variables calculated using Monte Carlo techniques for a sample size of 100,000. Again the probability distributions for the daily average values and for the single day are shown. As expected, the uncertainty for the average is much smaller than for the single day because of the large day-to-day and seasonal variability. In fact, the relative width in Figure 5 (see Schaffner et al. [19]) varies from 3\% to $12 \%$ for the daily averages and from $10 \%$ to $35 \%$ for the single day. 
The added value of a probability density distribution compared to a simple calculation of the mean is as follows: it allows the ranges of the variables as well as the probability that they are below or above a certain target value to be calculated. For example, Fig. 5 shows that average daily water use lies between 424 and 510 1/hh and day with a probability of $80 \%$. The water use for a single day lies between 336 and $634 \mathrm{l} / \mathrm{hh}$ and day, respectively, with the same probability. The same applies to the other key variables shown in Fig. 5.

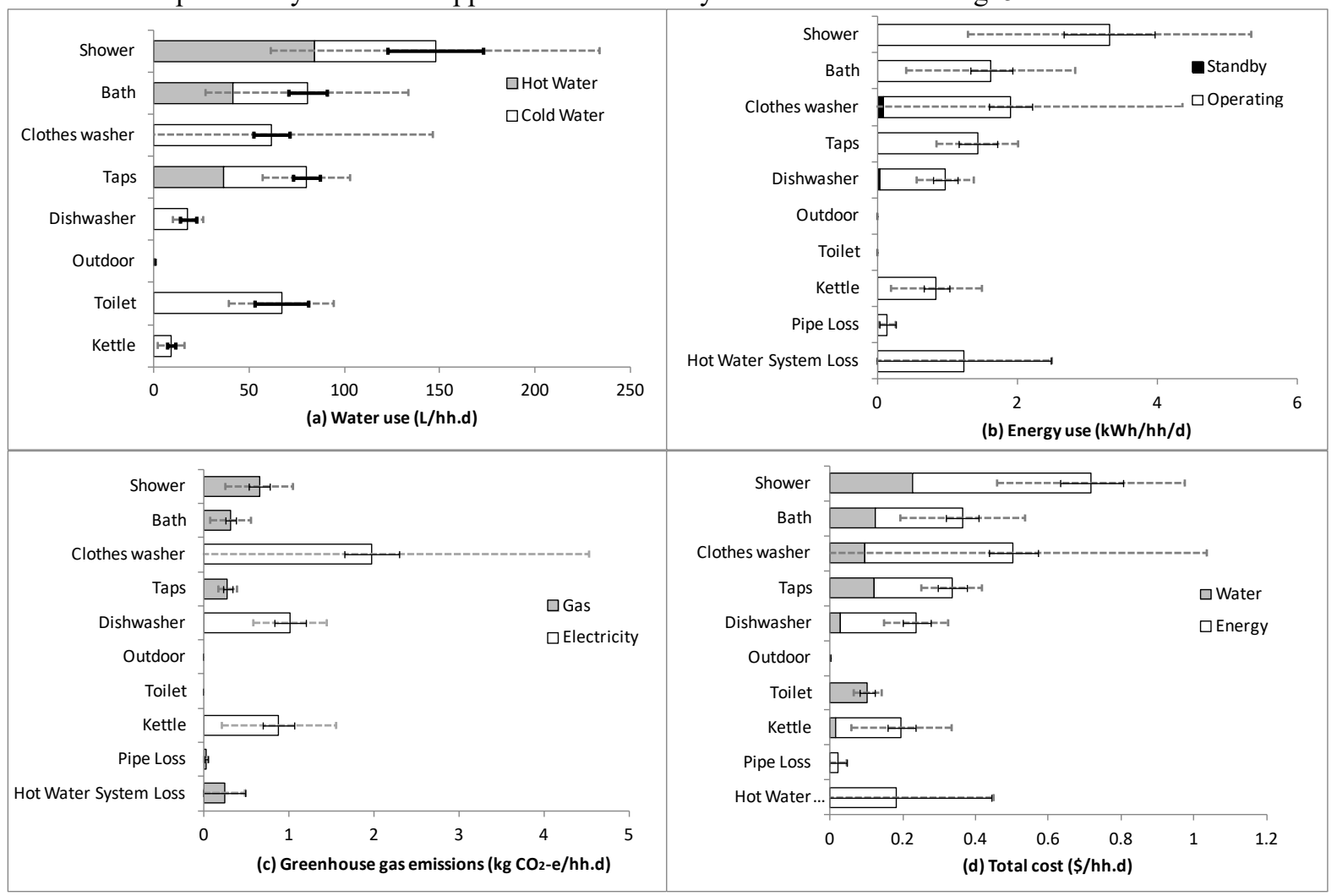

Fig. 4: Water use, energy use, greenhouse gas emissions and total costs for the shower, bath, ...kettle subsystems. The smaller black error bars represent the "STDV-average-day" and the larger grey ones the "STDV-singleday". 

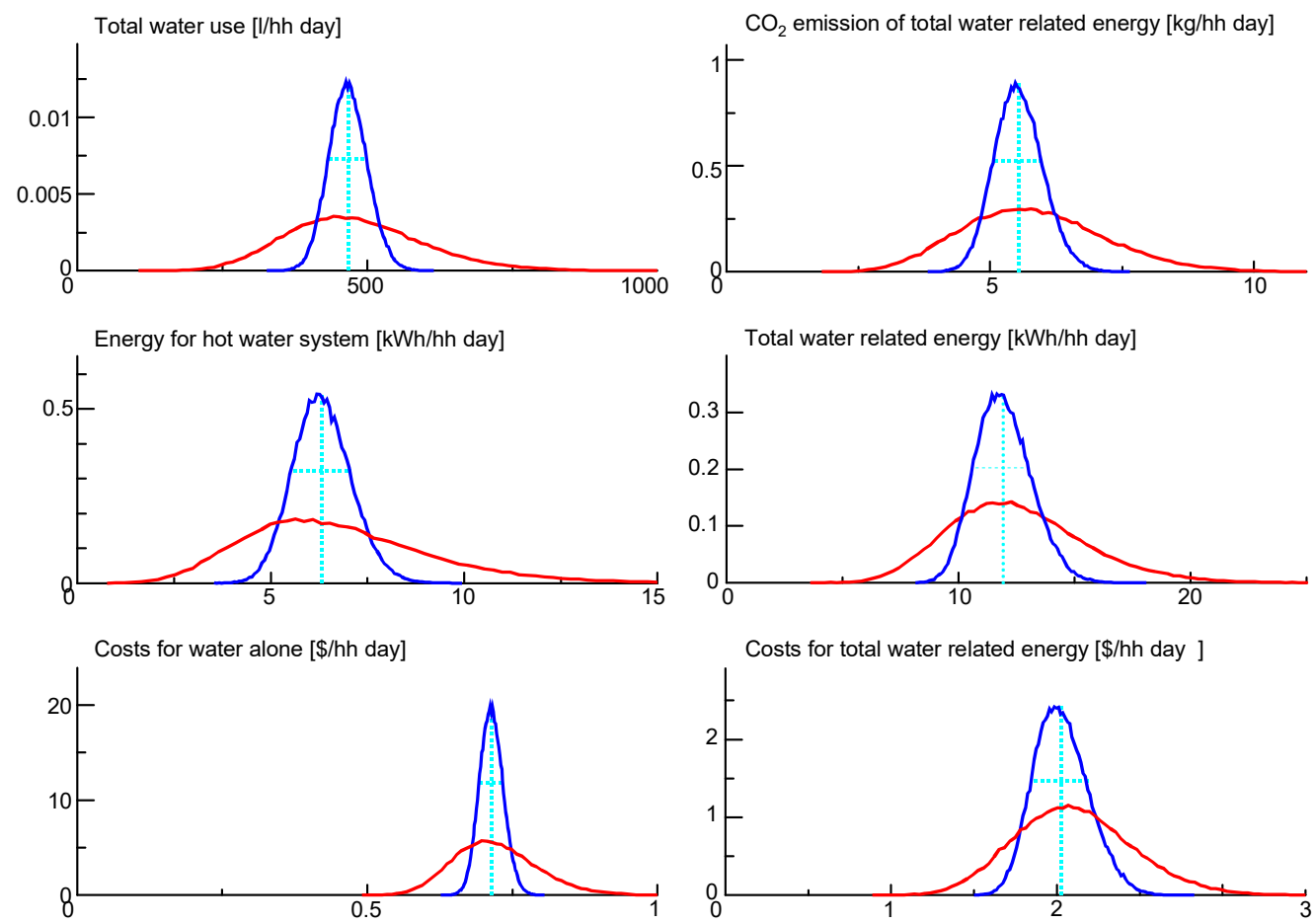

Figure 5: Probability density distributions for selected key variables. The narrower distribution shows the daily averages and the broader one the distribution for a single day. The dashed line represents the mean and standard deviation.

It's important to determine which parameter uncertainties are most responsible for the uncertainties of the selected variables. A parameter uncertainty ranking (Brun et al. [38]) showing which parameter uncertainty contributes how much to the STDV of a certain variable provides the answer.

As expected, the result of the analysis presented in Table 4 shows that the parameters for which no time series were available (P15, P22, P24, P70, P36, P4, P61, P49) dominate the uncertainty for the case of the STDV for the "average day". It should be pointed out that the figure for the "STDV-average-day" is quite small with $10 \%$. If a further reduction should be needed, time series measurements for the above parameters would be required.

Table 4: Cumulative uncertainty rankings for the "STDV-average-day" and "STDV-single-day" for waterrelated energy

\begin{tabular}{|c|c|c|c|}
\hline \multicolumn{2}{|l|}{ Average day } & \multicolumn{2}{|l|}{ Single day } \\
\hline Parameter & \begin{tabular}{|l|} 
Cumulative \\
uncertainty \\
ranking in \%
\end{tabular} & Parameter & $\begin{array}{l}\text { Cumulative } \\
\text { uncertainty } \\
\text { ranking in \% }\end{array}$ \\
\hline P15 Heat coefficient hot water storage & 64.6 & P43Number of cycles warm front per day & 28.4 \\
\hline P22 Flowrate per showers for adults & 76.5 & P1 Number of adults per household & 44.1 \\
\hline P24 Temperature of showers for adults & 80.2 & P3 Temperature of cold water & 59.3 \\
\hline P70 Temperature of hand wash & 82.3 & P15 Heat coefficient hot water storage & 67.8 \\
\hline P36 Temperature of baths for child & 84.4 & P23 Number of showers per adult per day & 73.0 \\
\hline P4 Temperature of hot water at HWS & 86.3 & P21 Flow duration per shower for adults & 78.0 \\
\hline P21 Flow duration per shower for adults & 88.0 & P44 Number of cycles hot front per day & 82.2 \\
\hline P61 Temperature of warm cycle front & 89.8 & P32 Number of baths per adult per day & 86.2 \\
\hline P49 Volume per cycle warm front & 91.3 & P27 Number of showers per child per day & 89.8 \\
\hline
\end{tabular}

For the "STDV-single-day", the parameter uncertainty ranking in Table 4 shows that the uncertainty is dominated by parameters with large daily variability (P43, P1, P23, P21, P44, P32, P27) and those with large seasonal variability (P3). It should be pointed out that the variability cannot be reduced by collecting larger datasets or more accurate measurements as opposed to the uncertainty of the daily average.

\subsection{Sensitivity analysis and scenarios}


A first insight into possible reduction measures of water and energy use is provided by a local sensitivity analysis showing the local change of the variables for small changes in the parameters. This analysis allows those parameters with the greatest influence on key variables to be identified and is basic for a careful scenario analysis yielding possible reduction measures (see Schaffner et al. [22]). However, the local sensitivity analysis works only for continuous parameters but not for discrete ones such as the switch between standard (gas/electric) and solar hot-water systems (P20). Accordingly, we do not show the results of the sensitivity analysis but will proceed straight with the scenario analysis.

For the various scenarios, the parameters have been classified into the following four groups:

1) Parameters which were not changed either because we did not want to change them such as occupancy or length of pipes, or because they are environmental parameters such a temperature of cold water, ambient temperature.

2) Technical parameters such as heat loss coefficients and the energy used for washing machines.

3) Technical parameters with behavioural assistance such as flowrates per shower for adults and children.

4) Behavioural parameters such as flow duration and temperature of showers.

For each parameter of Groups 2 and 3, both the potential and realistic reductions have to be found (see Schaffner et al. [22]).

The basic assumption for the scenarios was that the "level of service" remains at least on the current level. Examples include that personal hygiene remains on an accepted level, clothes are still washed, cooling / heating is still possible and watching TV remains enjoyable (same screen size, quality).

The difference between potential and realistic reductions is that the latter mean no change in comfort and service (whereas potential reductions may cause a slight decrease in comfort but not in service). For example, the temperature of showers for adults is currently $41^{\circ} \mathrm{C}$, whereas the realistic value was seen as $38^{\circ} \mathrm{C}$ and the potential one as $35^{\circ} \mathrm{C}$.

The realistic and potential values for the "technical" parameters were carefully evaluated with the manufacturers of household appliances. The corresponding values for the "behavioural" parameters were estimated by discussions among selected stakeholders. Those for the "technical parameters with behavioural assistance" were evaluated with manufacturers and stakeholders. It should be pointed out that the realistic values are rather conservative in the sense of providing the same comfort. The resulting parameters for the scenarios are also shown in Table 2. A total of 107 parameters were evaluated for potential and realistic reduction measures. Each combination of these 107 parameters leads to a specific scenario. These can be classified into the groups of "1parameter", "2-parameter", $\ldots$ and "107-parameter" scenarios. The "n-parameter" scenario means that $n$ parameters out of the 107 parameters are changed. The total number of scenarios is exactly the sum of the number of scenarios in each group, namely $\sum_{n=1}^{107}\left(\begin{array}{c}107 \\ n\end{array}\right)=2^{107}-1$ which is a huge number.

where $\left(\begin{array}{c}107 \\ n\end{array}\right)$ are binomial coefficients.

It is clear that it is impossible to calculate each of these scenarios. However, in order to get an insight into the possible reduction potential, we calculated the "1-parameter" scenarios and the scenarios including all technical and behavioural changes and the combination of both respectively. Table 5 presents the results for the " 1 parameter" scenario with a solar HWS and for the combined scenarios. The six selected key variables defined above, namely total water use, $\mathrm{CO}_{2}$ emission of total water-related energy, energy for hot-water system, total water-related energy, costs for water alone and costs for total water-related energy are shown.

Table 5: Results of scenario analysis. Selected key variables for the scenarios discussed above. For the parameter values $(\mathrm{P})$ refer to Table 2 .

-* In principle, the household uses the same amount of energy for heating up the water with a solar HWS. However, as solar energy is not relevant to primary energy and $\mathrm{CO}_{2}$ emissions, it is omitted from the table

\begin{tabular}{|c|c|c|c|c|c|c|c|c|c|c|c|c|}
\hline \multirow[t]{2}{*}{ Scenario } & \multicolumn{2}{|c|}{ Total water use } & \multicolumn{2}{|c|}{$\begin{array}{l}\mathrm{CO}_{2} \text { emission of } \\
\text { total water- } \\
\text { related energy }\end{array}$} & \multicolumn{2}{|c|}{$\begin{array}{l}\text { Energy for hot } \\
\text { water system }\end{array}$} & \multicolumn{2}{|c|}{$\begin{array}{l}\text { Total water- } \\
\text { related energy }\end{array}$} & \multicolumn{2}{|c|}{$\begin{array}{l}\text { Costs for water } \\
\text { alone }\end{array}$} & \multicolumn{2}{|c|}{$\begin{array}{l}\text { Costs for total } \\
\text { water-related } \\
\text { energy }\end{array}$} \\
\hline & [1/hh day $]$ & $\%$ & $\begin{array}{l}{[\mathrm{kg} / \mathrm{hh}} \\
\text { day] }\end{array}$ & $\%$ & $\begin{array}{l}{[\mathrm{kWh} / \mathrm{hh}} \\
\text { day] }\end{array}$ & $\%$ & $\begin{array}{l}{[\mathrm{kWh} / \mathrm{hh}} \\
\text { day }]\end{array}$ & $\%$ & $\begin{array}{l}{[\$ / \mathrm{hh}} \\
\text { day] }\end{array}$ & $\%$ & $\begin{array}{l}{[\$ / \mathrm{hh}} \\
\text { day] }\end{array}$ & $\%$ \\
\hline Current state & 464 & & 5.40 & & 6.37 & & 11.5 & & 0.71 & & 1.95 & \\
\hline Technical potential & 444 & 96 & 4.57 & 85 & 6.25 & 98 & 9.46 & 82 & 0.70 & 99 & 1.66 & 85 \\
\hline
\end{tabular}




\begin{tabular}{|c|c|c|c|c|c|c|c|c|c|c|c|c|}
\hline Technical realistic & 444 & 96 & 4.65 & 86 & 6.25 & 98 & 9.73 & 85 & 0.70 & 99 & 1.69 & 87 \\
\hline Solar HWS & 464 & 100 & 3.87 & 74 & -* & -** & 3.72 & 32 & 0.71 & 100 & 0.80 & 41 \\
\hline $\begin{array}{l}\text { Technical +solar HWS } \\
\text { potential }\end{array}$ & 444 & 96 & 3.34 & 62 & $-*$ & $-*$ & 3.21 & 28 & 0.70 & 99 & 0.73 & 37 \\
\hline $\begin{array}{l}\text { Technical +solar HWS } \\
\text { realistic }\end{array}$ & 444 & 96 & 3.37 & 62 & $-*$ & $-*$ & 3.24 & 28 & 0.70 & 99 & 0.72 & 37 \\
\hline $\begin{array}{l}\text { Technical+solar } \\
\text { HWS+washer/dishwasher } \\
\text { connected to hot and cold } \\
\text { water potential }\end{array}$ & 444 & 96 & 1.84 & 34 & $-*$ & $-*$ & 1.77 & 15 & 0.70 & 99 & 0.42 & 22 \\
\hline $\begin{array}{l}\text { Technical+solar } \\
\text { HWS+washer/dishwasher } \\
\text { connected to hot and cold } \\
\text { water realistic }\end{array}$ & 444 & 96 & 1.86 & 34 & $-*$ & $-*$ & 1.79 & 16 & 0.70 & 99 & 0.41 & 21 \\
\hline $\begin{array}{l}\text { Technical with } \\
\text { behavioural assistance } \\
\text { potential }\end{array}$ & 279 & 60 & 4.89 & 91 & 3.8 & 60 & 8.9 & 77 & 0.6 & 85 & 1.73 & 89 \\
\hline $\begin{array}{l}\text { Technical with } \\
\text { behavioural assistance } \\
\text { realistic }\end{array}$ & 353 & 76 & 5.04 & 93 & 4.55 & 71 & 9.64 & 84 & 0.64 & 90 & 1.79 & 92 \\
\hline Behavioural potential & 185 & 40 & 2.53 & 477 & 1.22 & 19 & 4.53 & 39 & 0.54 & 76 & 1.25 & 64 \\
\hline Behavioural realistic & 281 & 61 & 3.89 & 72 & 2.24 & 35 & 6.66 & 58 & 0.60 & 85 & 1.52 & 78 \\
\hline $\begin{array}{l}\text { Technical+behavioural } \\
\text { potential }\end{array}$ & 108 & 23 & 1.63 & 30 & 1.09 & 17 & 2.46 & 21 & 0.49 & 69 & 0.71 & 36 \\
\hline $\begin{array}{l}\text { Technical+behavioural } \\
\text { realistic }\end{array}$ & 202 & 44 & 2.83 & 52 & 1.80 & 28 & 4.37 & 38 & 0.55 & 77 & 1.08 & 55 \\
\hline $\begin{array}{l}\text { Technical+behavioural+ } \\
\text { solar } \\
\text { HWS+washer/dishwasher } \\
\text { connected to hot and cold } \\
\text { water, potential }\end{array}$ & 108 & 23 & .79 & 15 & $-*$ & $-*$ & 0.76 & 7 & 0.49 & 69 & 0.20 & 10 \\
\hline $\begin{array}{l}\text { Technical+behavioural } \\
\text { +solar } \\
\text { HWS+washer/dishwasher } \\
\text { connected to hot and cold } \\
\text { water, realistic }\end{array}$ & 202 & 44 & 1.39 & 26 & $-*$ & $-*$ & 1.33 & 12 & 0.55 & 77 & 0.32 & 16 \\
\hline
\end{tabular}

Table 5 shows that the reduction potential for water, $\mathrm{CO}_{2}$ emissions, water-related energy, water costs and water-related energy costs are $4-77 \%, 14-85 \%, 15-93 \%, 1-31 \%$ and $13-90 \%$ respectively depending on the measures taken. Technical measures alone, i.e. without changing to a solar HWS, lead to the smallest reduction whereas the combined scenario, namely technical + behavioural + solar HWS + connection of washer/dishwasher to the HWS, naturally lead to the highest reduction. Technical changes with behavioural assistance have the potential to save a lot of water, namely up to $30 \%$. Behavioural changes alone are very effective. In fact, they account for up to $75 \%$ of the whole possible reduction of water and water costs, twothirds of $\mathrm{CO}_{2}$ emissions and water-related energy and just over one-third of the water-related energy costs.

Remark: In Table 5, the costs for the water-related energy for the "Technical + Solar HWS potential" scenario are slightly higher than for the realistic scenario, which seems rather strange. In fact the total electrical energy costs are lower for the potential case than for the realistic one, as expected. However, the water-related energy is $3 \%$ higher for the potential than for the realistic case, which explains this unexpected fact.

\section{Conclusions}

Systematic application of the mathematical material flow analysis to the problem of water-related energy in households permitted a detailed analysis of the services and activities in the Milton household that account for specific amounts of water, energy, $\mathrm{CO}_{2}$ emissions and related costs. The model developed allowed us to investigate and discuss possible reduction measures in detail.

The method represents a complementary approach to huge "data-mining" and monitoring programs. In fact, it offers the benefit of gaining a system understanding from a rather limited database (the current system knowledge) without conducting extended measurement campaigns. 
The study showed that technical improvements alone without changing to a solar HWS in the Milton household result in a less than about $15 \%$ reduction in energy and $\mathrm{CO}_{2}$ emissions. This is because this is already equipped at a high technical level. The technical improvements required for other types of household might be much greater. Technical improvements with behavioural assistance offer a large potential for water saving.

Behavioural changes have the potential to be very effective in terms of water saving and reduction of waterrelated energy and $\mathrm{CO}_{2}$ emissions, namely by about $50 \%$ or even more. The major advantages of behavioural changes are a) no additional costs are involved, b) no change in installations or infrastructure is needed, c) they can be applied immediately, and d) each individual can apply them independently.

The most effective technical measure would be the installation of a solar HWS combined with the connection of washing machines and dishwashers to a hot water source (rather than using coal-fired electricity to heat water within the machine). This would lead to a reduction of about $70 \%$ in water-related energy and about $25 \%$ in $\mathrm{CO}_{2}$ emissions. However, this measure would require changes in installations and associated costs.

It should be pointed out that replacing a washing machine connected to a natural-gas operated HWS to a waterefficient washing machine using coal-fired electricity to heat the water internally would result in an increase in greenhouse gas emissions.

The analysis presented in this paper underlines the importance of detailed household analyses in order to understand key factors determining the water, water-related energy and $\mathrm{CO}_{2}$ emissions of households. Since households are the building block of cities, acquiring a high understanding of them is crucial to understanding the cities themselves. Therefore the next step is to extend the analysis to the different types of households in a city, which is currently in progress. (The model has been designed so that it can be applied to a whole city.)

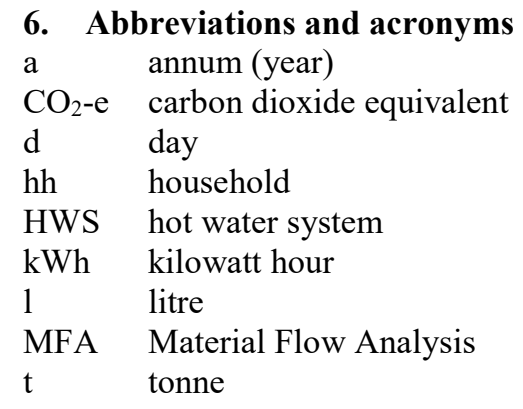

\section{Acknowledgements}

The authors gratefully acknowledge the support given by the Urban Water Security Research Alliance, including the Queensland Government, CSIRO, the University of Queensland and Griffith University, and The Swiss Federal Institute for Environmental Science and Technology (Eawag). The support of the AustralianAmerican Fulbright Commission is also appreciated. We are also appreciative of the data provided by the Bureau of Meteorology, SEQWater, Queensland Urban Utilities, AGL energy and Energex. 


\section{Appendix A. Equations for the shower subsystem.}

Water used for shower:

$$
\begin{aligned}
& X_{w}=X_{w}^{(\text {Adult })}+X_{w}^{(\text {Child })} \\
& X_{w}^{(\text {Adult })}=P_{1} \cdot P_{21} \cdot P_{22} \cdot P_{23} \\
& X_{w}^{(\text {Child })}=P_{2} \cdot P_{25} \cdot P_{26} \cdot P_{27}
\end{aligned}
$$

Where $X_{w}, X_{w}^{(\text {Adult })}$ and $X_{w}^{(\text {Child })}$ is the total water used by adults and children.

\section{Energy used for shower:}

$$
\begin{aligned}
& E_{w}=X_{h w} \cdot\left(P_{4}-P_{3}\right) \cdot c_{p} \\
& X_{h w}=X_{h w}^{(\text {Adult })}+X_{h w}^{(\text {Child })} \\
& X_{w}^{(\text {Adult })}=X_{h w}^{(\text {Adult })}+X_{c w}^{(\text {Adult })} \\
& X_{h w}^{(\text {Adult })}=\frac{P_{24}-P_{3}}{P_{4}-P_{3}} \cdot X_{w}^{(\text {Adult })}
\end{aligned}
$$

A similar set of equations was used for children.

$E_{w}$ is the energy used for the shower, $X_{h w}$ the hot water, $X_{h w}^{(\text {Adult })}$ and $X_{h w}^{(\text {Child })}$ the hot water used by adults and children and $c_{p}$ the specific heat of water $\left(0.001103 \mathrm{kWh} / \mathrm{kg} \cdot{ }^{\circ} \mathrm{K}\right)$.

Refer to Table 2 for the parameter values.

\section{Appendix B: Loss equations}

\section{Energy loss by water storage system:}

For the case of stored water held at a constant temperature $T_{h w s}$ the losses in the time interval $\Delta t$ are:

$$
\Delta E_{\text {storage_loss }}=\Delta t \cdot h \cdot O \cdot\left(T_{h w s}-T_{\text {env }}\right)
$$

For the case of stored water heated up periodically to a temperature $T_{h w s}$ the losses in the time interval $\Delta t$ are:

$$
\Delta E_{\text {storage_loss }}=h \cdot O \cdot\left(T_{h w s}-T_{\text {env }}\right) \cdot \frac{\left(1-e^{-\alpha \cdot \Delta t}\right)}{\alpha}
$$

where:

$$
\alpha=\frac{h \cdot O}{m \cdot c_{p}}
$$

$h=P_{15} \quad$ Heat coefficient of hot water storage

$O=P_{16} \quad$ Surface of hot water storage

$m=\quad$ Water capacity of storage $[\mathrm{kg}]$

$T_{h w s}=P_{4} \quad$ Temperature of hot water

$T_{\text {env }}=P_{6} \quad$ Ambient temperature of the hot-water storage system

\section{Energy loss by hot water pipes:}

Hot water in pipes loses energy through:

1) Heating up the pipe

2) Convection and radiation from the pipe

3) Cooling off of standing water in the pipe

More precisely, when hot water is used, first of all the pipe is always heated immediately, secondly it loses energy to the environment, and thirdly the standing water in the pipe cools off. 
1) Heating up the pipe:

To a very good approximation, the energy loss is:

$$
\Delta E_{\text {heat }}=v \cdot 2 \pi \cdot r \cdot d \cdot l \cdot \rho_{c o} \cdot C_{c o} \cdot\left[T_{h w s}-T_{e n v}\right]
$$

$$
\begin{array}{ll}
v=P_{18} & \text { Number of cycles } \\
r=P_{13} & \text { Radius of the pipe } \\
d=P_{19} & \text { Thickness of the pipe } \\
l=P_{11} & \text { Length of the pipe } \\
\rho_{c o} & \text { Density of the pipe } \\
c_{c o} & \text { Specific heat of the pipe }
\end{array}
$$

2) Cooling and radiation from the pipe:

$$
\Delta E_{\text {conv }}=h_{\text {pipe }} \cdot 2 \pi \cdot r \cdot l \cdot\left[T_{h w s}-T_{e n v}\right] \cdot \frac{V_{h w}}{\pi r^{2} \cdot v_{0}}
$$

$h_{\text {pipe }}=P_{14} \quad$ Heat coefficient of the pipe

$V_{h w} \quad$ Volume of hot water used per day

$v_{0}=P_{12} \quad$ Velocity of hot water

3) Cooling of the standing water in the pipe:

$$
\Delta E_{\text {stand }}=v \cdot c_{p} \cdot\left[T_{h w s}-T_{e n v}\right] \cdot \rho_{w} \cdot \pi \cdot r^{2} \cdot l
$$

$$
\rho_{w}=1000 \frac{\mathrm{kg}}{\mathrm{m}^{3}} \quad \text { Density of water }
$$

Clearly, (eq. 4c) is only valid if the cooling off of the standing water is complete. For shorter cooling times, the loss is smaller.

It can easily be seen that eq. (4a) - (4c) represent upper limits for the energy loss of a hot water pipe. In the simulations, eq. (4a)-(4c) were used, representing an upper limit for the loss of hot water pipes.

\section{Appendix C: Basic statistical formulas:}

$P_{i}^{(n)}: \quad \mathrm{n}=1, \ldots, \mathrm{N}:$ data points for parameter $P_{i}$

a) Average:

$$
\bar{P}_{i}=\frac{1}{N} \sum_{n=1}^{N} P_{i}^{(n)}
$$

b) Variance of a single day:

$$
\sigma^{2}=\frac{1}{N-1} \sum_{n=1}^{N}\left(P_{i}^{(n)}-\bar{P}_{i}\right)^{2}
$$

c) Variance of an average day:

$$
\sigma_{\bar{P}}^{2}=\frac{1}{N} \sigma^{2}
$$

d) Variance of Group 3 parameters:

$$
\sigma^{2}=\frac{1}{N-1} \sum_{n=1}^{N}\left(P_{i}^{(n)}-\overline{P_{i}}\right)^{2} \approx \frac{1}{N-1} \sum_{n=1}^{N}\left(P_{i}^{(n)}-P_{\text {Seas }, i}^{(n)}\right)^{2}+\frac{1}{N-1} \sum_{n=1}^{N}\left(P_{\text {Seas }, i}^{(n)}-\overline{P_{i}}\right)^{2}
$$

where : $P_{\text {Seas }, i}^{(n)}$ is the (smoothed) seasonal trend of $P_{i}^{(n)}$, namely: 


$$
\begin{aligned}
& P_{\text {Seas }, i}^{(n)}=\frac{1}{N_{0}} \sum_{m=n-\Delta n}^{n+\Delta n} P_{i}^{(m)} \cdot e^{-\frac{\left(t_{n}-t_{m}\right)^{2}}{2 \sigma^{2}}} \\
& N_{0}=\sum_{m=n-\Delta n}^{n+\Delta n} e^{-\frac{\left(t_{n}-t_{m}\right)^{2}}{2 \sigma^{2}}} \text { is the normalisation factor and } \Delta n \text { and } \sigma \text { are } 20 \text { and } 10 \text { days respectively for }
\end{aligned}
$$

our time series of air and drinking-water temperatures.

The first term on the right hand side of eq. $(5 \mathrm{~d})$ is the variability from day to day and the second term the seasonal variability.

\section{References}

1. $\quad$ ABS (2011) AS4604.0 Energy Account Australia 08-09.

2. IEA (2011) Statistics and balances for OECD countries. Online statistics and balances.

3. IEA, Key World Energy Statistics, International Energy Agency, Editor. 2010, OECD and International Energy Agency: Paris.

4. Dür, Promote new relation between technology and human development. Lecture Record. 1996: Tokyo Japan.

5. AGO, Australian National Greenhouse Accounts. 2010, Australian Department of Climate Change and Energy Efficiency: Canberra.

6. Kenway, S.J., P. Lant, and A. Priestley, Quantifying the links between water and energy in cities. Journal of Water and Climate Change. 2011. 2(4): p. 247-259.

7. Queensland Water Commission, South East Queensland Water Strategy, Queensland Water Commission, Editor. 2010: Brisbane.

8. Cheng, C.-L., Study of the Inter-Relationship between Water Use and Energy Conservation for a Building Energy and Buildings, 2002. 34: p. 261-266.

9. Arpke, A. and N. Hutzler, Domestic Water Use in the United States. A Life-Cycle Approach. Journal of Industrial Ecology, 2006. 10(1-2): p. 169-183.

10. Flower, D.J.M., An Integrated Approach to Modelling Urban Water Systems, in Department of Civil Engineering. 2009, Monash University: Melbourne. p. 373.

11. Butler, D., A Small-Scale Study of Wastewater Discharges from Domestic Appliances. Journal of the Chartered Institution of Water and Environmental Management. 1991. 5(2): p. 178-185.

12. Mayer, P.W., W.B. DeOreo, E.M. Opitz, J.C. Kiefer, W.Y. Davis, B. Dziegielewski, and J.O. Nelson, Residential End Uses of Water, American Water Works Association Research Foundation, Editor. 1999: Denver, USA.

13. Jacobs, H.E. and J. Haarhoff, Structure and data requirements of an end-use model for residential water demand and return flow. Water SA, 2004. 30(3): p. 293-304.

14. Jacobs, H.E. and J. Haarhoff, Application of a residential end-use model for estimating cold and hot water demand, wastewater flow and salinity. Water SA, 2004. 30(3): p. 305-316.

15. Roberts, P., Yarra Valley Water 2003 Appliance Stock and Usage Patterns Survey, Yarra Valley Water, Editor. 2004: Melbourne, Australia.

16. Roberts, P. Yarra Valley Water 2004 Residential End Use Measurement Study. 2005 [cited 200723 May]; Available from: http://www.yvw.com.au/NR/rdonlyres/983166CA-B506-4C08-8B955EDD378CFB53/0/REUMSReportFinal.pdf.

17. White, S., G. Milne, and C. Riedy, End use analysis: Issues and lessons. Water Science and Technology: Water Supply, 2004. 4(3): p. 57-66.

18. Leontieff, W.W. and A.A. Stroud, Multiregional input-output analysis, in Structural Interdependence and Economic Development, T. Barna, Editor. Macmillan: London, UK. P. 119-149. 1963.

19. Baccini, P. and P.H. Brunner, Metabolism of the anthroposphere. 1991, Berlin: Springer Verlag.

20. Kwonpongsagoon, S., H.-P. Bader, and R. Scheidegger, Modelling cadmium flows in Australia on the basis of a substance flow analysis. Clean Techn Environ Policy, 2007. 9: p. 313-323.

21. Huang, D.-B., H.-P. Bader, R. Scheidegger, R. Schertenleib, and W. Gujer, Confronting limitations: New solutions required for urban water management in Kunming City. Journal of Environmental Management, 2007. 84: p. 49-61.

22. Schaffner, M., H.-P. Bader, and R. Scheidegger, Modeling the contribution of point sources and nonpoint sources to Thachin River water pollution. Science of the Total Environment, 2009. 407: p. 49024915.

23. Baccini, P. and H.-P. Bader, Regionaler Stoffhausholt: Erfassung, Bewertung und Steuerung. 1990, Heidleberg: Spektrum Akademisher Verlag.

24. Commonwealth of Australia, National Greenhouse Accounts (NGA) Factors. 2008, Canberra, Australia: Australian Government Department of Climate Change. 
25. WSAA, WSAA Report Card 2008-2009. Performance of the Australian Urban Water Industry and projections for the future. 2009.

26. AGL (2010) AGL Natural Gas Prices, Brisbane North and Ipswich.

27. Origin Energy (2010) Tariffs for Residential Customers.

28. Bureau of Meteorology, Climate Data Online, in Site 40913, 2007-2009 years monthly mean min and max temperatures. 2010. Australian Government.

29. SEQ Water, Daily water temperature records for Mt Crosby water intake, S. Kenway, Editor. 2011, SEQ Water. Brisbane.

30. Engineering Toolbox. Thermal conductivity of some common materials. 2011 - 12 April 2011; Available from: http://www.engineeringtoolbox.com/thermal-conductivity-d 429.html.

31. Rheem, Hot Water Manual. 2006: Rheem Australia Pty Ltd ABN 21098823511.

32. Miele, Operating instructions for washing machine W149, Model Number. 05681 810, M. Novotronic, Editor. 2002.

33. Mills, D., Greenhouse Gas Emissions from Energy Use in Queensland Homes $2^{\text {nd }}$ Revision. 2009, Queensland Department of Environment and Resource Management, Sustainability Innovation Division.: Brisbane.

34. Heinrich, M., Water End Use and Efficiency Project (WEEP) - Final Report - in BRANZ Study Report 159. 2007.

35. Commonwealth of Australia, Energy Use in the Australian Residential Sector 1986-2020. 2008, Canberra: Commonwealth of Australia. Department of the Environment, Water, Heritage and the Arts.

36. Rosen, K. and M. Alan, Energy use of U.S. consumer electronics at the end of the 20th century. Lawrence Berkeley National Laboratory, Editor. 2000.

37. National Water Commission, National Performance Report 2008-09 - urban water utilities. Part C. 2010.

38. Brun, R., P. Reichert, and H.R. Künsch, Practical identifiability of large environmental simulation models. Water Resources Research, 2001. 37: p. 1015-1030. 